\title{
Towards reliable design-by-analysis for divertor plasma facing components - guidelines for inelastic assessment (part 1: unirradiated)
}

\author{
M Fursdon ${ }^{1}, \mathrm{~J}-\mathrm{H} \mathrm{You}^{2}, \mathrm{M} \mathrm{Li}^{2}$ \\ 1 CCFE, Culham Science Centre, Abingdon, OX14 3DB, UK, \\ 2 Max-Planck-Institut für Plasmaphysik, Boltzmannstr. 2, 85748 Garching, Germany, \\ Email: mike.fursdon@ukaea.uk
}

Keywords: plasma facing component, structural integrity analysis, inelastic, elastoplastic, divertor.

\begin{abstract}
.
Guidelines are presented for the recommended method of assessing by analysis the structural integrity of divertor plasma facing components (PFCs) under high heat flux (HHF) loads. The objective is to enable analysis to provide greater supporting evidence for PFC qualification (which for ITER is currently achieved by test alone) and to provide reasonable estimates of irradiated PFC performance where component test data is limited or non-existent. Typically, PFCs comprise tungsten armour, CuCrZr heat-sink and copper interlayer. For more reliable assessment of this type of construction, two shortfalls in existing elastic analysis methods have been addressed. Firstly, the scope of assessment rules has been extended to cover armour failure (e.g. by deep cracking) and secondly the accuracy of analysis is increased by using inelastic analysis methods to address complexities created by PFC's multi-material block like construction. These complexities arise mainly from the dissimilar yield strengths and thermal expansion coefficients of the component materials. This paper details the proposed "low temperature" design code rules in the guidelines, which are based on a combination of existing inelastic code rules plus a set of methodologies devised specifically for PFC structures. The failure mechanisms of exhaustion of ductility, fast-fracture, fatigue and ratcheting are addressed, and the process of assessment is demonstrated by means of an example analysis on an ITER-like monoblock component in its unirradiated condition. In two followup papers, creep rules and methods for estimating the HHF structural integrity of an irradiated component using sparse irradiated materials data are presented. In the unirradiated condition it is shown that fatigue and armour cracking performance dominate predicted structural integrity, but when irradiated, exhaustion of ductility is expected to be more prevalent. It is argued that with these more rigorous assessment methods, a significant step has been made towards developing reliable design-by-analysis methods for predicting the expected HHF structural integrity performance of divertor PFC designs.
\end{abstract}

\section{Introduction}

In ITER, the divertor is the component with the highest design steady state heat loads (Merola [25]) of circa $10 \mathrm{MW} / \mathrm{m}^{2}$ (with excursions to $20 \mathrm{MW} / \mathrm{m}^{2}$ ). While these loads are already demanding, in (EU)DEMO (the proposed European demonstration power plant) conditions are expected to be more arduous with longer pulse times and higher levels of irradiation (estimated at up to 10dpa (You 2016[1]). To meet this expectation, EUROfusion are carrying out research and development on the next generation divertor components (as described by You [26], [1]).

For this development, much guidance is drawn from the experiences of ITER divertor development both in design and qualification. A typical DEMO divertor PFC concept is similar to the ITER design comprising a tungsten armour block with through $\mathrm{CuCrZr}$ cooling pipe joined to the tungsten via a soft copper interlayer (see Fig 1). Like ITER, assessment of DEMO designs is currently by high heat flux (HHF) testing (Greuner [36]), based again largely on the ITER specification (Morola [25]) of 5000 cycles at $10 \mathrm{MW} / \mathrm{m}^{2}$ and 300 cycles at $20 \mathrm{MW} / \mathrm{m}^{2}$. If a component fails, the predominant mode of failure in ITER and DEMO mock-ups is by cracking of the armour (as shown in Fig 2), although failure of the heatsink cooling pipe and interlayer is also reported (Gavali [27]).

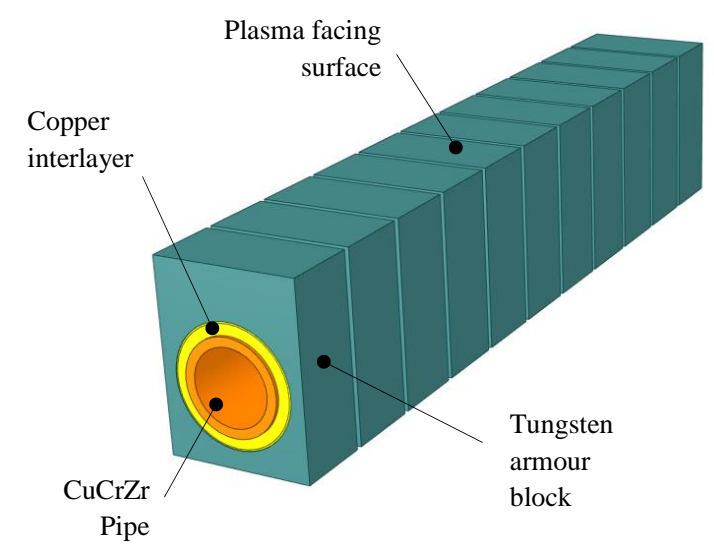

Figure 1 Section from typical divertor plasma facing component comprising a series of individual tungsten armour blocks surrounding a $\mathrm{CuCrZr}$ cooling pipe with copper interlayer. 


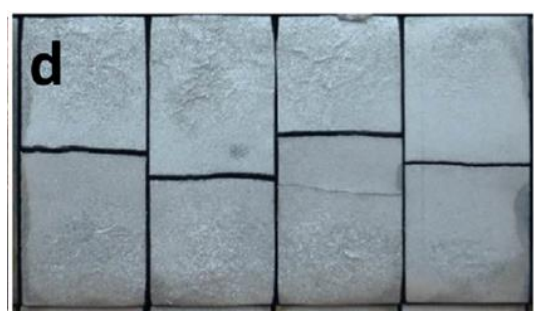

Figure 2 Deep cracking in the armour of an ITER divertor PFC mock-up following HHF test Typical taken from [Gavali[27]]

ITER have now demonstrated the required PFC performance using tests (Sun [31]) but is instructive to note that divertor component qualification tests have not historically been accompanied by extensive preceding analysis supporting the anticipated performance. Although discrete analysis studies have been published for DEMO (e.g. by Li Puma [6] and Crescenzi [28]) and failure modelling has been used to diagnose problems (Li [15]), for ITER at least it remains the case that it is mandatory to validate design "by experiments" (rather than analysis) (Hirai [24]). This begs the question about the perceived value of analysis as an accurate predictor of PFC structural integrity in HHF load conditions.

In this paper the case for analysis as a viable and necessary tool for assessing PFCs is presented. It is emphasised that analysis is particularly required for DEMO in its current state of development, and that despite the shortfalls in current analysis methods, these can be overcome, by a combination of new and existing alternative methods. To make the point the paper presents a detailed set of guidelines for the preferred method of assessing plasma facing components and this is demonstrated by an example analysis of an ITER-like component.

\subsection{Shortfalls in current PFC structural integrity assessments attempts}

One reason why analysis is not relied upon to support current PFC qualification is that it fails to predict one of the dominant failure mechanisms experienced in HHF tests: the cracking of the armour. This is because current methods of assessment (which use standard elastic code rules) can only be applied to the nominal structural component i.e., the pipe. It follows then, for analysis to be successful, the scope of the structural integrity assessment process needs to be extended to include the armour. However, this is not straight-forward because, to the authors knowledge, there are no formally validated assessments methods relevant to brittle materials such as tungsten, so these methods need to be devised. Towards this end recent work by $\mathrm{Li}$ has suggested one potential mechanism for cracking which can be adopted in a design rule format. Nonetheless others are required.

Furthermore, even application of the existing code rules for assessing the ductile structural (sub)components in PFCs presents its own problems. This is partly because codes are derived from the analysis of pressure vessels (i.e., thin-walled axisymmetric structures) and hence are not ideally suited to the multi-material block-like construction of PFCs. This was demonstrated by Fursdon [2] who showed that stresses in the multi-material monoblock components bear little resemblance to the stress predicted by the conventional/common elastic code methodology.

The problem created by the multilateral construction of PFCs is mainly due to two factors. The first is the different coefficient of thermal expansion (CTE) of the subcomponent materials. This creates (at least in a monoblock) significant through-thickness residual stress developed during cooling in the joining processes (Fursdon [2]). The second is the difference in yield strength of these materials. This creates material dependant limits on the loads transferred between subcomponents.

To overcome both these complexities Fursdon [5] concludes elastoplastic analysis must be used. (i.e., where yielding is explicitly modelled). Although this adds an extra level of complexity and unfamiliarity in analysis, this does not mean that the method of formal structural integrity code assessment is in entirely "new territory", since existing design codes already provide design rules for assessment using elastoplastic (and even inelastic) analysis methods (ASME [10], RCC-MR [33] and ITER SDC-IC [3]).

Even though these code methods have existed for some time, it is acknowledged that these rules seem rarely to be applied (to the author's knowledge). Perhaps this is because in the design of existing conventional nuclear components, thinwall single-material methods are deemed appropriate such that the severity of plasticity, if it occurs, can be estimated (e.g by a Neuber curve approach as described in [3]). However there also appears to be little application of elastoplastic rules in the fusion community either, where bulky components with multi-material construction are more prevalent. There may be a reluctance because of the increased analysis time and potential convergence issues, but it is suggested that these disadvantages are far outweighed by the significant increase in relevance of the results produced.

It is an aim of this paper to encourage and promote the use inelastic methods in the assessment of PFC components so that the much-needed reliable analysis data can be provided to support concept design proposals. This is not only to add the usual benefits of analysis as product development tool ${ }^{(1)}$, but also to address a particular need in DEMO that analysis seem best suited to satisfy.

\subsection{Analysis as an essential part of DEMO component qualification}

Of the many benefits offered by analysis in component development the one that appears to stand out for DEMO is the potential for a greater understanding of the effects of irradiation. Degradation by neutron irradiation is expected to be particularly significant in DEMO (You et al [1]) and might create the limiting case when the resulting effect on component performance is determined. Although tests of irradiated components have been done [32], these pose many practical problems, and are not realistic in the concept development phase of development (i.e. the current DEMO status). It follows that in order to provide the necessary data on irradiated performance this will probably need to be supplied through analysis methods (albeit as an estimate).

(1) Cost an efficiency and the ability to investigate load case not practical to test such as combined heat flux and EM loads cases 
The significance of the potential irradiation effect is emphasised by the scale of material property change possible. This is illustrated for example by the pre-post irradiation stress strain curve of copper as shown in Fig. 3 (with a fivefold increase in yield stress and complete loss of hardening), and the change in available elongation in $\mathrm{CuCrZr}$ as shown in Fig 4. (with a drastic reduction of ductility at temperatures below $150^{\circ} \mathrm{C}$ ). Although these changes can be expected to significantly alter component stress/strain levels and material limits, with appropriate analysis, the effects of these factors can be assessed.

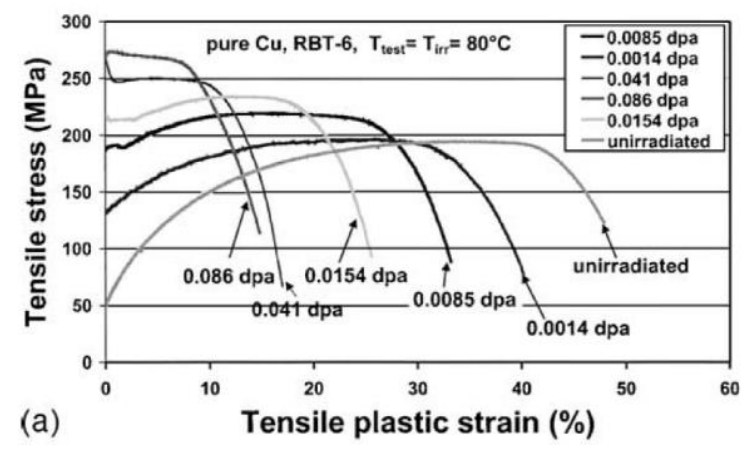

Figure 3 Effect of neutron irradiation on the engineering stress strain curves of pure copper $\left(\mathrm{T}_{\text {test }}=\mathrm{T}_{\text {irr }}=80^{\circ} \mathrm{C}\right)$ Fabritsiev [29]

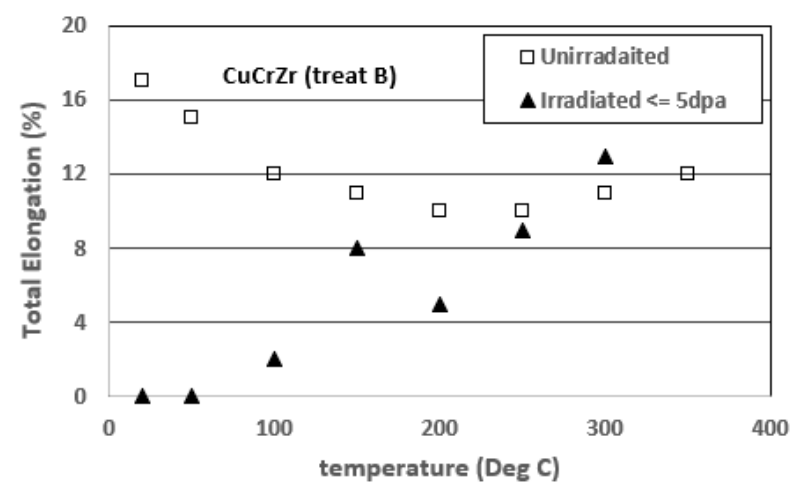

Figure 4 Effect of irradiation of the ductility of $\mathrm{CuCrZr}$ (here shown by the minimum measure total elongation) data from SDC-IC appendix $\mathrm{A}[22]$

\subsection{Towards reliable PFC design by analysis}

In the long term EUROfusion plan to produce a document known as the Demo Design Criterion (DDC) in 2025 [4] with recommended structural integrity assessment criterion for all DEMO plasma facing components. However, for the immediate needs of the divertor R\&D (where design assessment of current concepts is required now), the EUROfusion's divertor design group has created a set of preliminary guidelines known as the Inelastic Analysis Procedure (IAP). The IAP is the subject of this paper.

In the existing design codes (whether elastic or elastoplastic) many failure mechanisms are assessed. The minimum set covered by ASME[10], RCCMR[33] and SDC_IC [3] is plastic collapse, fatigue, ratcheting and creep. To these, SDC_IC and ASME add exhaustion of ductility and (SDC-IC) fast fracture. Much of the testing done to date suggests that failure by repeated cycling is the prime focus of failure assessment (e.g. failure by fatigue or perhaps ratcheting). However, if (as is argued) the irradiated "embrittled" condition is potentially the worst-case scenario, then it is possible that ductility or fast fracture becomes the limiting failure mode (i.e., from reduced allowable strain or from reduced fracture toughness). To this the potential for failure by creep must be added given the potential for high temperatures under high heat loads. No single code was found to be ideal for assessing all the above failure mechanisms in PFCs. Rather the IAP uses extracts from all the above codes to create the appropriate rule definitions. The details and rationale for the recommended rule created are detailed in Section 2 of this paper

\subsection{Peculiarities of PFC structural integrity assessment.}

It has already been highlighted that PFC assessment goes beyond normal structural integrity assessment convention by needing to include the assessment of the nominally nonstructural armour material. There are also other particular features of PFCs that need special consideration.

To account for susceptibility of PFCs to potentially significant residual stress (discussed above) the recommended method of analysis includes an initial analysis step to simulate the manufacturing cycle as described for example by Li and You [15]. For PFCs with a CuCrZr pipe, the methods proposed in the IAP is to simulate the cooling from either the $\mathrm{CuCrZr}$ hardening temperature if a braze process is used (as in [34]), or the pressing temperature if hot radial pressing process is used (ref [35]). The method and rationale for this is detailed in previous work by the divertor group in reference [2].

The presence of multiple dissimilar metal joints in PFCs creates ongoing analysis challenges. Such joints risk the creation of stress/strain singularities in analysis as highlighted by Kelly [8] (with theoretically infinite values in peak stress or strain) which invalidate structural integrity assessment. A method proposed in the IAP to overcome this issue is by use of the hot spot method (for example as described EN 13445 [7]). However, this method requires prior test information on similar style joints and is currently only applied to fatigue evaluation. Alternatively, since stress singularities are an indication of a severe stress concentration, it is suggested that the design, rather than the assessment method should be modified (for example, by the methods outlined by Kelly [8] and illustrated in the example analysis described below in Section 3).

Special methodologies are also required to account for the changing properties of PFC material due to high levels of irradiation as demonstrated in Figure 3. This is achieved by using material property change commands within the assessment analysis, so that strain usage before and during irradiation can be accumulated appropriately. The change in allowable strain is accounted for by use of usage fraction as detailed in Section 2.1.2.

Finally, as described in previous work [6], assessment of water cooled PFCs requires an assessment of the cooling water 
critical heat flux limit (the limit of nucleate boiling heat transfer). In the IAP this is achieved using the method described in reference [2] and is not discussed further here.

\subsection{Scope}

This paper gives a detailed description of the elasto-plastic rules used in the guidelines under conditions (temperatures) where creep is expected to be negligible (termed here "low temperature" rules). A negligible creep curve defining allowable time at temperature for a valid "low temperature" assessment will be presented in part \#3 of this paper. To support the rule description an example assessment of an unirradiated ITER like monoblock is presented in which examples of specific methodologies are shown. In follow-up papers, methods and data collection for estimating PFC performance in their irradiated condition are described as well as rules for assessing creep damage when the negligible creep criterion is not met.

The guidelines focus on the structural integrity assessment under nominally normal $10 \mathrm{MW} / \mathrm{m}^{2}$ heat flux operating conditions and "slow transient" excursions to $20 \mathrm{MW} / \mathrm{m}^{2}$. Confirmation of assessment methods for fast transient load cases (such as ELM loading and disruption electromagnetic loading) and plastic collapse rules is ongoing.

The development of armour assessment rules is also under development and only preliminary armour rules are presented here. Further rules are anticipated as test data experience is accumulated.

While focussing on the design of divertor components made from $\mathrm{CuCrZr}$, copper and Tungsten, it is the intention that the IAP can be applied to all multi-material plasma facing components including the use of materials such as Eurofer or variants (e.g. for target designs as described in [37]). Within the example analyses presented, a simple example assessment of ratcheting for a steel piped monoblock is given to suggest this wider applicability.

\section{Rule definitions}

The following section details the IAP rules, the rationale for their selection, and where appropriate, a recommended assessment methodology.

\section{$2.1 \quad$ Ductile material rules}

\subsubsection{Plastic collapse}

Plastic collapse is driven by excess primary loads (i.e. loads that do not significantly reduce with deformation of the structure) which for a PFC are mostly caused by dead weight, coolant pressure or EM loads. Provisionally the recommended rule for plastic collapse is as defined by SDC-IC IC 3121.1.2 (Elasto-plastic analysis -Immediate plastic collapse). This is provisional because plastic collapse has not yet been seen as a driving design failure mode for the main current concern of normal operating conditions (Thermal load cases). Confirmation is expected when abnormal (EM) loading conditions are considered.

\subsubsection{Immediate exhaustion of ductility}

The Immediate exhaustion of ductility rule compares the expected plastic strain against the limiting strain at rupture of a material. The rule is expected to be highly significant in the assessment of components in their irradiated conditions where materials can lose nearly all ductility (as shown by Figure 4). It is a prime example where analysis can expose design flaws which cannot be shown by the current qualification testing of unirradiated components, and as such supports the argument that analysis data should play an essential part in the justification of any divertor PFC concept design.

Proposed rule:

Show that the local accumulated strain usage from pre and post irradiation (and from manufacturing) does not exceed the materials multiaxial true strain at rupture.

Relevant rules

1) ASME 5.3 Protection Against Local Failure 5.3.3 ElasticPlastic Analysis [10]

2) SDC-IC 3121.3.2 Elasto-plastic analysis (Local fracture, exhaustion of ductility) [3]

Rationale: Aspects of both ASME and SDC-IC are used in the derivation of this rule. In general, ASME was deemed the more appropriate because a) it includes the effects of manufacturing strains and b) it accounts for the effects of multiaxial stress covering a greater range of conditions than other codes [11]. However, when accounting for pre and post irradiation the technique presented in SDC-IC is relevant (as discussed below). The IAP incorporates both codes by requiring the ASME equation (equation 1 below) to be satisfied, but in a manner using SDC-ICs usage fraction methodology to capture pre and post irradiation effects (as shown by equation 4 below).

$$
\begin{gathered}
\varepsilon_{p e q}+\varepsilon_{c f} \leq \gamma_{d} \cdot \varepsilon_{L}(T, \Phi) \ldots(1) \\
\text { where: } \\
\varepsilon_{\text {peq }}=\text { equivalent plastic strain (in operations). } \\
\varepsilon_{\text {cf }}=\text { equivalent manufacturing strain. } \\
\gamma_{\mathrm{d}}=\text { safety factor }(0.5) \\
\varepsilon_{L}=\text { multiaxial strain limit (function of } \\
\text { temperature } \mathrm{T} \text { and fluence } \Phi) .
\end{gathered}
$$

The multiaxial strain limit $\varepsilon_{L}$ is determined from uniaxial test data $\varepsilon_{L U}$ and an exponential function (which, unlike the SDC-IC variant, allows for negative triaxiality)

$$
\begin{aligned}
& \varepsilon_{L}(T, \emptyset)=\varepsilon_{L U}(T, \emptyset) * K t f(T) \\
& K t f(T, \sigma)=\exp \left(-\left(\frac{\alpha_{S L}}{1+m}\right)\left(\left\{\frac{\sigma_{1}+\sigma_{2}+\sigma_{3}}{3 \sigma_{e q}}\right\}-\frac{1}{3}\right)\right)
\end{aligned}
$$

Where

$$
\begin{aligned}
& \alpha_{S L}=\text { material parameter }(=2.2 \text { for } \mathrm{Cu}) \\
& m=2^{\text {nd }} \text { material parameter }(0.5) \\
& \sigma_{1}, \sigma_{2}, \sigma_{3}, \sigma_{e q v}=\text { the three primary stress and } \\
& \text { equivalent stress respectively. } \\
& T=\text { temperature }
\end{aligned}
$$


$\varnothing=$ Fluence $/$ dpa

The change in a material's ductility pre and post irradiation, is accounted for by use of ductility "usage fractions" $\left(\mathrm{U}_{\mathrm{d}}\right)$ (similar to the creep usage fraction methodology described by SDC-IC for accumulated load step effects IC-2765). The sum of "pre" and "post" irradiation usage must be less than one:

$$
\mathrm{U}_{\mathrm{d}-\text { pre }}+\Delta \mathrm{U}_{\mathrm{d}-\text { post }}<1
$$

where the strain usage " $\mathrm{U}_{\mathrm{d}-\mathrm{xxx}}$ " is defined as follows:

$$
\begin{aligned}
& \mathrm{U}_{\mathrm{d}-\text { pre }}=\left(\varepsilon_{\text {peq }}+\varepsilon_{c f}\right) /\left(\gamma_{\mathrm{d} .} \varepsilon_{\mathrm{Lpre}}\right) \\
& \mathrm{U}_{\mathrm{d}-\text { post }}=\Delta \varepsilon_{\text {peq-irr }} /\left(\gamma_{\mathrm{d}} \cdot \varepsilon_{\mathrm{Lpost}}\right)
\end{aligned}
$$

and

$$
\Delta \varepsilon_{\text {peq-post }}=\text { post irradiation incremental plastic strain }
$$

All the variables in the above expressions (strain, rupture strain, triaxiality factor etc.) are functions of temperature and/or stress. Since these vary significantly in the material volume being assessed, it is necessary to evaluate the above expressions throughout this volume to ensure the maximum value is correctly identified. (This can be done in ANSYS for example by using "user defined results" which effectively allows whole result distributions (e.g. contour plots) to be considered as variables, which can then be used in mathematical expression to form resultant ductility usage contour plots.)

It should be noted that flow localisation is not seen as a failure mechanism in the IAP. Rather it is seen as a potentially beneficial mechanism for further strain redistribution. Ultimately excessive flow localisation will be captured by exhaustion of ductility criterion.

\subsubsection{Immediate fast fracture}

In design assessments the ideal situation of perfect manufacture is considered. However, there is a limit to which material quality can be assured in terms of defect size (eg because of NDT resolution). This means that even in nominally perfect material, defects below the detectable size could cause stress concentration with stress intensities that might exceed the materials fracture toughness, and so cause fast fracture. Like exhaustion of ductility, this is unlikely to be exposed in the unirradiated case where materials have high ductility and so good fracture toughness but might be expected to be a concern in the irradiated "embrittled" condition. However, in practice, materials data suggests fracture toughness is not as affected by irradiation as the terminology implies, so it remains to be seen if, under irradiation, this failure mechanism is as significant as, say, exhaustion of ductility.

\section{Proposed rule:}

Show that the maximum value of stress intensity $K$ (caused by undetected material flaws) is less than the critical stress intensity factor Kc assuming a minimum detectable pennyshaped flaw size of $0.2^{(1)} \mathrm{mm}$.

\section{Relevant rule:}

1) SDC_IC 3121.4.2 Fast fracture

$$
\begin{aligned}
& K_{1}<\gamma_{\mathrm{K} 1} K_{c}(T, \emptyset) \\
& K_{1}=\sigma_{1} \sqrt{\frac{4 a}{\pi}}
\end{aligned}
$$

where

$\sigma 1=$ maximum of maximum principal stress

$\mathrm{a}=$ radius of void $(0.1 \mathrm{~mm})$

$\gamma_{\mathrm{K} 1}=$ safety factor $(0.67)$ in accordance with SDC-IC

Footnote (1) or size appropriate to expected NDT

Rationale. As discussed above, the assessment of immediate fast fracture is made with the assumption that the material is flaw free to the limit of measurability i.e. by NDT. In this case, it is then only necessary to show that any flaws at or below this limit do not cause fast fracture. This "flaw tolerance" philosophy is based on that outlined by SDC_IC (IC2112.3).

In this rule, the proposed procedure deviates from the recommended elastoplastic rule methodology. Ideally a full elastoplastic analysis would show that the $\mathrm{J}$ integral of a defect in any possible location is less than the local critical $\mathrm{J}$ value. However, it is not necessarily possible to know the location of the maximum $\mathrm{J}$ integral without assessing all possible locations. Since $\mathrm{J}$ integral calculations are normally conducted at a single location alone with explicit crack meshing, the assessment of all possible locations is not practical.

For the IAP, an approximation is made using the linear stress intensity factor $\mathrm{K}_{1}$ (where $\mathrm{K}_{1 \mathrm{C}}=\sqrt{ }\left(\mathrm{J}_{\mathrm{c}} \mathrm{E}\right.$ ) ), and the postulation of possible penny shaped flaws. In this case the distribution of potential "flawed material" $\mathrm{K}_{1}$ can be evaluated directly from the distribution of the maximum principal stress $\sigma_{1}$ using equation (6).

(Note: Since local value of $\mathrm{K}_{1 \mathrm{C}}$ also varies with temperature, for ease of inspection the IAP recommends the use of a fast fracture usage fraction $\left(\mathrm{U}_{\mathrm{k}}\right)$, where $\mathrm{U}_{\mathrm{k}}=\mathrm{K}_{1} / \mathrm{K}_{1 \mathrm{C}}$. The distribution of usage can then be presented as a distribution to highlight critical areas).

\subsubsection{Ratcheting}

The ratcheting rule exposes the potential for the progressive growth of strain or deformation leading to component failure or loss of function. Its detection in PFC design is important, because it potentially causes two forms of failure (following the distinction defined by Rudolph et al [12]). Firstly, ratcheting can cause thinning of the cooling pipe wall until eventually failure occurs due to plastic collapse. This type of failure is termed global ratcheting since it affects component functionality on a macro scale. Secondly, even if no excessive thinning of the pipe occurs, ratcheting can lead to localised growth of plastic strain that eventually causes failure due to exhaustion of ductility (manifesting itself by crack formation and subsequent fast fracture or accelerated fatigue). This is termed local ratcheting since it causes only localised effects while macro performance is nominally unaffected.

As emphasised above, ductility (plastic strain) limits only become significant in the irradiated case. In the absence of physical testing of irradiated components, it appears therefore 
that only analysis can currently expose flaws in a proposed PFC design associated with local ratcheting.

The method of detecting ratcheting is by the explicit cycleby-cycle study of displacement/strain development. The preferred way to pass the ratcheting rule is to first show a stabilised strain or displacement response is achieved. It must then also be shown that both the resulting component condition passes functional requirements, and that plastic strains do not exceed the exhaustion of ductility rule.

For infrequent upset condition ratcheting is allowable provided it can be shown by the explicit simulation of all cycles that in the resulting final stress/strain state the standard functional and material-allowable requirements are met.

Following the above definitions of ratcheting (global or local) two separate rules are proposed to differentiate between the two forms of potential failure.

\subsubsection{Local ratcheting (local strain limits):}

Proposed rule:

Using a material model capable of simulating material ratcheting ${ }^{(1)}$, demonstrate that under cyclic loading the end-oflife strains resulting from any local strain ratcheting obey the exhaustion of ductility rule.

\section{Relevant rules:}

1) SDC-IC 3131.2.2 Significant local plastic strain (Elasto-plastic, ratcheting)

Rationale / Methodology. In the IAP development studies using the Chaboche material model, local strain ratcheting was often displayed - particularly at stress concentrations. In these cases, it was only possible to discern a "final" trend in strain development by simulating many tens of cycles. The apparent delay in developing a distinct final trend was attributed to the masking effects of early shakedown and elastic follow-up. When (or if) a final trend is observed, the final end-of-life strain can be determined by extrapolation and the result subjected to the exhaustion of ductility rule.

Footnote (1): The accuracy of material ratcheting effect predicted by any material model is still a matter of debate [13]. The Chaboche model (as available in ANSYS for example) allows some material ratcheting effect to be simulated, but more sophisticated models exist, suggesting the assessment methodology requires further work.

\subsubsection{Global ratcheting (S3)}

Proposed rule:

Using an elastic perfectly-plastic material model, demonstrate that under cyclic loading the maximum displacement of any point in the component converges, and that component functionality is retained.

Relevant rules

1) ASME VIII DIV2 5.5.7 Ratcheting Assessment Elastic-Plastic Stress Analysis
Rationale / Methodology: For global ratcheting assessment a simple elastic perfectly-plastic material model is used (similar to ASME [10]). This is done to remove the above local material ratcheting mechanisms and so simplify and speed-up the process of identifying global ratcheting trends. It is also necessary to remove any temperature dependence of the yield stress in the model to avoid a further multi-material ratcheting effect first observed by Silberschmidt [14].

Since the elastoplastic global ratcheting assessment does not provide a quick one-step criterion for showing compliance (such as the $3 \mathrm{Sm}$ rule or Bree diagram expression), a usage value or reserve factor is not provided by a single analysis. Rather this must be determined by a series of (potentially time consuming) exploratory analyses at higher loads to expose the failure condition (as illustrated by example in section 3.2.3.2).

\subsubsection{Fatigue}

Proposed rule:

Show that the local total of all fatigue usage fraction from all load combinations is less than 1.

Relevant rules:

For example, SDC-IC 3132.3.2 [3] Limits on fatigue damage. Most codes concur on this rule criterion.

$$
V_{j}\left(\Delta \varepsilon_{j}\right)=\frac{n_{j}}{N_{j}\left(\Delta \varepsilon_{j}\right)}
$$

$$
\Sigma V j<1 \quad \ldots(8)
$$

Where (for every load case j):

$\Delta \varepsilon j=$ intensity of strain range for the $\mathrm{j}^{\text {th }}$ load case

$V j=$ fatigue usage fraction at the jth load case

$n=$ number of cycles required at the $\mathrm{j}$ load case

$N_{j}=$ number of cycles to failure (from design

fatigue curve at $\Delta \varepsilon_{\mathrm{j}}$ ) at the jth load case

Rationale / Methodology: In the assessment of fatigue there are no specific requirements for monoblock assessment beyond the existing elastoplastic methods used in current codes. Here the calculated total strain increment ${ }^{1}$ is used directly against Manson Coffin strain life data.

When summing usage fractions from different load cases, it the usage fraction values used must be taken at the same location. A recommended method of achieving this is by creating contour plots of fatigue usage. (For example, in ANSYS by using the user defined result methodology discussed above for exhaustion of ductility).

Footnote (1): the strain increment value used should be evaluated by first calculating the strain increment in tensor form, noting that plastic and elastic components should also be calculated independently. The intensities of the elastic and plastic strain-increment tensors are then calculated separately before summing to determine the final strain increment value. 


\subsection{Armour materials}

Current HHF tests demonstrate that the ability to predict failure of the armour is one of the most important requirements of an analysis method used for PFC design justification. In the absence of existing formal code rules for typical (brittle) armour materials, to satisfy this requirement new rules need to be devised. Currently two rules are proposed. These should be viewed as provisional, pending further development.

The first rule aims to capture the predominant deep cracking failure seen in current tests. $\mathrm{Li}[15]$ postulated that this failure mechanism has two phases. The first involves plastic strain fatigue of the tungsten when it is in its ductile regime at temperatures above the ductile to brittle transition temperature (DBTT). This initiates small cracks which then fail by fast fracture when the tungsten returns to its brittle regime during excursions to temperatures below the DBTT (e.g. at standby). Li suggested this failure mechanism is particularly problematic when tungsten becomes recrystalised, when the material has lower yield strength leading to greater levels of plastic strain. The rule thus currently assumes that recrystallised layers have been formed, although it might viably be extended to noncrystalized material. (Strictly speaking this rule follows conventional ductile assessment methodologies since it deals with ductile material fatigue crack initiation).

The second rule aims to capture potential failure below the DBTT. Here only a basic assessment of ultimate strength is assessed following the textbook Ranking failure mechanism based on maximum principal stress.

\subsubsection{Recrystalised tungsten fatigue}

Proposed rule:

Show that the local total of all fatigue usage fraction (V) from all load combinations is less than 1 (taking into account the effects of DBTT)

The rule applied here is identical to the fatigue rule described in section 2.1.5, but consideration is made for the difference in fatigue life above and below the DBTT - following the methodology outlined by Li [15] (and as outlined below). The rule is only applied in cases where the armour material is expected to become recrystalised.

Note: $\mathrm{Li}$ also went on to determine if initiated cracks caused fast fracture. This step is not included in the IAP and consequently the proposed rule provides a conservative assessment of failure.

Methodology Identify regions in the tungsten expected to become recrystalised during service, for example from any material experiencing more than $1300^{\circ} \mathrm{C}$ under slow transient heat loads. This region is assigned elastoplastic material properties (to reflect the ductility possible at high temperatures). Incremental plastic strains above and below the ductile to brittle transition temperature are compared with the respective fatigue curves to obtain relevant fatigue lives (and so fatigue usage fractions).

\subsubsection{Ultimate strength.}

Proposed rule:

Show that the maximum principal stress is below the material ultimate strength (Rankine criterion).

$$
\sigma_{1}<\gamma_{W} \cdot \sigma_{U T S}(T, \emptyset)
$$

Where $\gamma_{\mathrm{W}}=0.5$

Methodology No specific method is proposed

\section{Example analysis and results}

The application of the above rules is demonstrated by an example assessment carried out of an ITER-like monoblock divertor component made from CuCrZr Copper and Tungsten (as illustrated in Figure 1) using ANSYS 18.2 workbench. The assessment includes a static thermal analysis and an elastoplastic static structural analysis (the former to define the temperature distributions used as inputs for the latter). The defined requirement for this example component is 5000 normal operation pulses of $2 \mathrm{hr}$ duration with 300 slow transient events of approximately 20 second duration (an estimation of anticipated normal DEMO operations).

\subsection{Model definition}

For both thermal and structural analysis, the monoblock was simulated by a quarter model with dimensions and typical mesh shown in Figure 5.

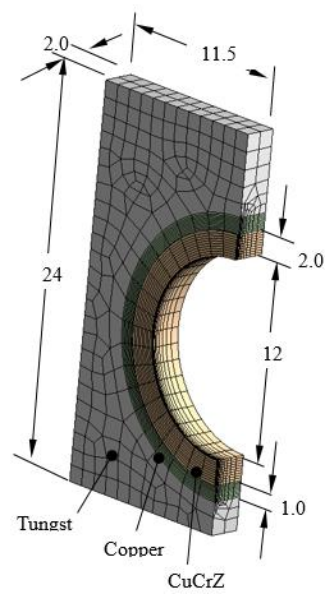

Figure 5 Quarter model geometry, dimensions and typical mesh using 23694 nodes. 


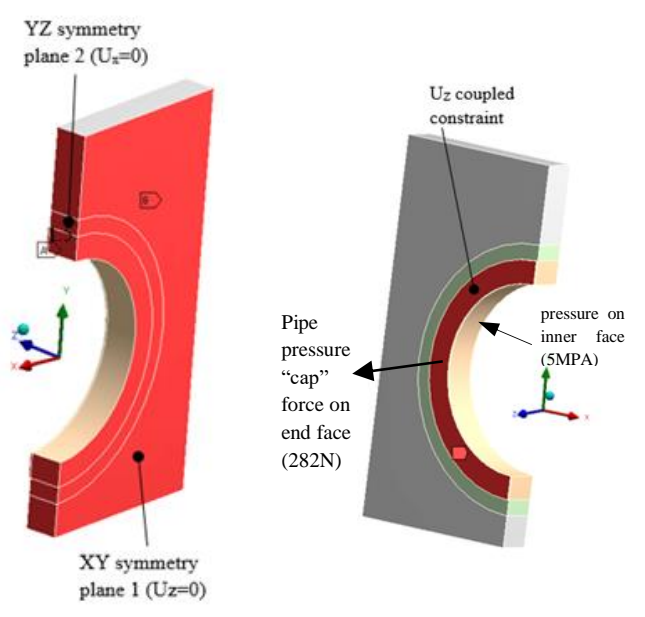

Figure 6 details of model constraints and pressure loading

\subsubsection{Thermal model}

The thermal analysis was performed with a uniform heat load of $10 \mathrm{MW} / \mathrm{m}^{2}$ or $20 \mathrm{MW} / \mathrm{m}^{2}$ applied to the plasma facing surface to represent respectively the normal and slow transient heat loads. A convective cooling condition was applied to the pipe bore with a coolant heat transfer coefficient determined according to the Sieder Tate correlation [16][17]. This was extracted using the Thermprop program [18] with water coolant flow of $16 \mathrm{~m} / \mathrm{s}$ at $5 \mathrm{Mpa}$ and $150^{\circ} \mathrm{C}$.

\subsubsection{Structural model and load cycles}

Chaboche material models were used to define elastoplastic properties for the copper and $\mathrm{CuCrZr}$. Separate models were used for immediate failure assessment (ductility, fracture) and cyclic failure assessment (fatigue and ratcheting) by matching the respective monotonic or cyclic stress-strain curves shown in literature. An elastic perfectly-plastic model was used for global ratcheting assessments (for reasons described in 2.1.4.2). Tungsten was defined as an elastic material (for simplicity) since the stress levels were found to remain within the elastic range. However, where recrystallization was expected (i.e. with reduced yield strength), elasto plastic properties were used and approximated by an elastic perfectly plastic model since detailed stress strain data was not available. All materials data is tabulated in the appendix.

Structural model boundary conditions are shown in Figure 6. A couple constraint on the pipe end face was used to simulate the prevention of pipe bending (simulating the expected constraint of the monoblock support system).

For a complete assessment, load cases of shutdown (uniform $20^{\circ} \mathrm{C}$ ), standby (uniform $150^{\circ} \mathrm{C}$ ), $10 \mathrm{MW} / \mathrm{m}^{2}$ and $20 \mathrm{MW} / \mathrm{m}^{2}$ would be considered, either singularly for monotonic rules or in (all) combinations for cyclic failure assessment. In the following, for brevity, only the shutdown and $20 \mathrm{MW} / \mathrm{m}^{2}$ load case results are shown.

For immediate failure assessment (ductility, fracture) a single application of the load is simulated, plus a preceding manufacturing cycle to capture the expected residual stress. In the example assessment given here, a brazing assembly method was simulated as described by Fursdon [2]). Here, the simulation is simplified to a single cooling cycle step from the point in the process where $\mathrm{CuCrZr}$ achieves its full strength (the final heat treatment cycle). This is achieved by imposing a uniform room temperature on the whole monoblock assembly with an assigned stress-free temperature of $470^{\circ} \mathrm{C}$ (The $\mathrm{CuCrZr}$ precipitation hardening heat treatment temperature). This is also similar to the simulation method described by $\mathrm{Li}[15]$ and Miskiewicz [19].

For cyclic failure assessment several cycles were applied to ensure a converged result is achieved. In this example assessment, 4 or 5 cycles were found to be sufficient in most cases but for local ratcheting up to 300 simulation cycles were required. As observed in reference [2], cyclic strain levels tend to be independent of residual stress, and hence there is no need to use a manufacturing step for cyclic failure assessment.

\subsection{Assessment of the CuCrZr pipe}

\subsubsection{Exhaustion of ductility}

Figure 7 and Figure 8 show the results set used for the evaluation of ductility usage according to the IAP method for the $20 \mathrm{MW} / \mathrm{m}^{2}$ load case. These are: $\operatorname{strain}(\varepsilon)$, triaxiality factor $(\mathrm{Ktf})$ uniaxial true strain at rupture $(\varepsilon \mathrm{LU})$ and resulting calculated multiaxial rupture strain $\left(\varepsilon_{\mathrm{L}}\right)$. Note that the highest strain occurs at the top of the pipe $(\varepsilon=0.012)$ but the effect of triaxiality has it's biggest effect at the bottom of the pipe $\left(\min \mathrm{K}_{\mathrm{Tf}}=0.16\right)$ and it is not easy to identify which factor will have the highest impact in usage. The high triaxiality is due to the large tensile strain caused by the constraint preventing pipe bending (reflecting the no-bending installation requirements). However, since the ductility of $\mathrm{CuCrZr}$ is very high in its unirradiated condition (with true strain at rupture $>100 \%$ ), the evaluated ductility usage at $20 \mathrm{MW} / \mathrm{m}^{2}$ and standby (as shown in Figure 9) is negligible, with a peak usage less than $5 \%$.

Conclusion: Assessemnt is passed (usage 5\%)

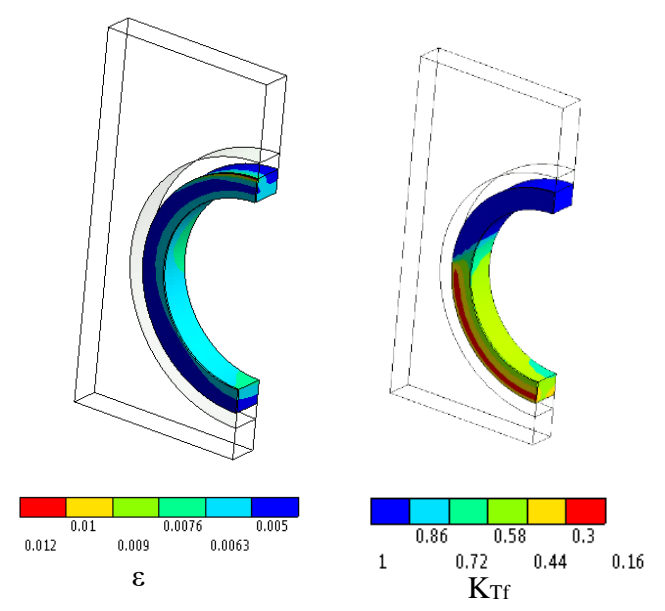

Figure 7 Distributions of strain $(\varepsilon)$ and triaxiality factor $\left(\mathrm{K}_{\mathrm{Tf}}\right)$ at $20 \mathrm{MW} / \mathrm{m} 2$ 

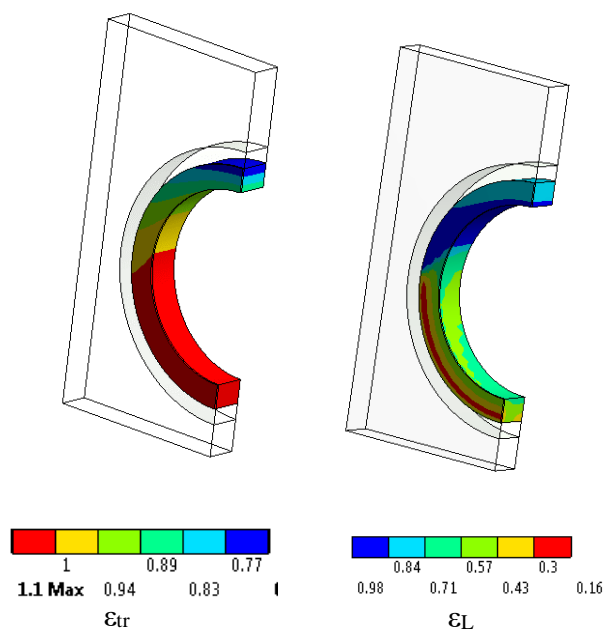

Figure 8 Distributions of uniaxial true strain at rupture $\left(\varepsilon_{\mathrm{Utr}}\right)$, and the limit strain $\varepsilon_{\mathrm{L}}$ (product of $\mathrm{K}_{\mathrm{Tf}}$ and $\varepsilon_{\mathrm{Utr}}$ )
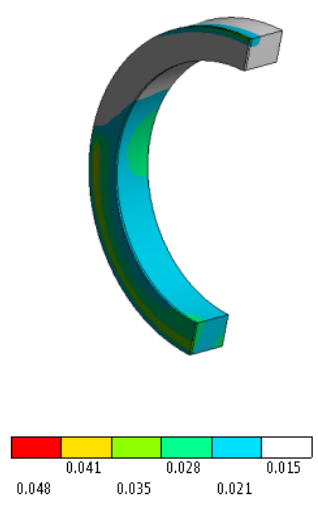

$\mathrm{U}_{\mathrm{d}}$
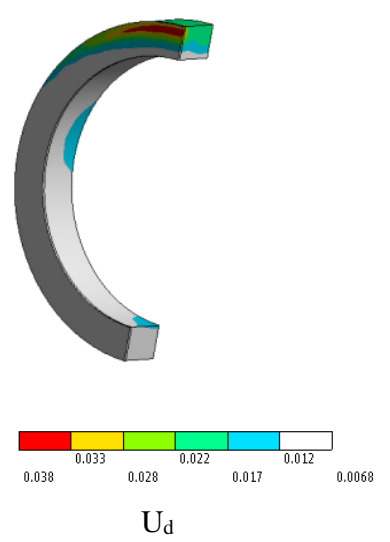

$\mathrm{U}_{\mathrm{d}}$
Figure 9 Distributions of ductility usage fraction $\left(\mathrm{U}_{\mathrm{d}}=\varepsilon / \varepsilon_{\mathrm{L}}\right)$ at $20 \mathrm{MW} / \mathrm{m}^{2}$ (left) and standby (right) showing that the maximum ductility usage is $4.8 \%$
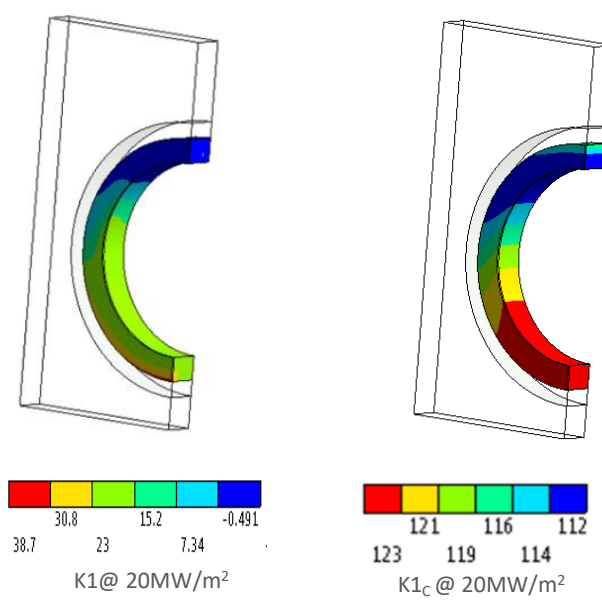

Figure 10 Distribution of Calculated stress intensity; local (temperature dependant) value of critical stress intensity at $20 \mathrm{MW} / \mathrm{m}^{2}$
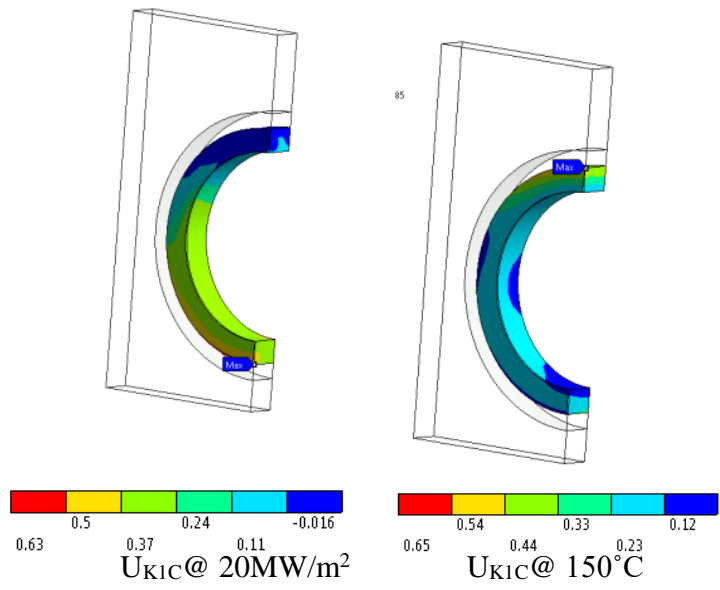

Figure 11 Distribution of Calculated stress intensity; local (temperature dependant) value of critical stress intensity at $20 \mathrm{MW} / \mathrm{m}^{2}$ and resulting usage fraction (with that at standby usage for comparison)

\subsubsection{Ratcheting}

\subsubsection{Local ratcheting}

For the effective cycle from standby to $20 \mathrm{MW} / \mathrm{m}^{2}$ heat load, local ratcheting is predicted to occur at the stress concentration created by the gap between adjacent monoblocks (see Figure 12). The strain is calculated to ratchet from $1 \%$ to more than $4 \%$ during the expected 300 slow transient events (Figure 13) assuming a worst case one event per pulse scenario. The multiaxial true strain at rupture for this condition is $84 \%$ (as shown in Figure 8), leading to a usage fraction of $9.5 \%$ (including the 0.5 "safety factor"). Hence this local ratcheting is not expected to cause failure in the unirradiated condition.

Note that many cycles are required to expose the local ratcheting effect (which appears initially to be masked by stable strain values in other areas). For the example shown, the analysis took 10 hours to solve raising an additional concern regarding the viability of local ratcheting simulation (further to the material models concerns discussed above).

Conclusion: Assessement is passed (usage 9.5\%) 

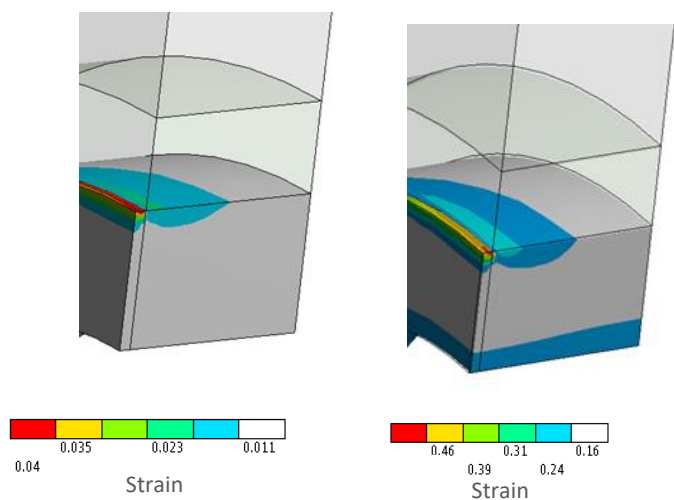

Figure 12 Distribution of strain at $10 \mathrm{MW} / \mathrm{m}^{2}$ (left) and $20 \mathrm{MW} / \mathrm{m}^{2}$ (right) after 300 cycles.

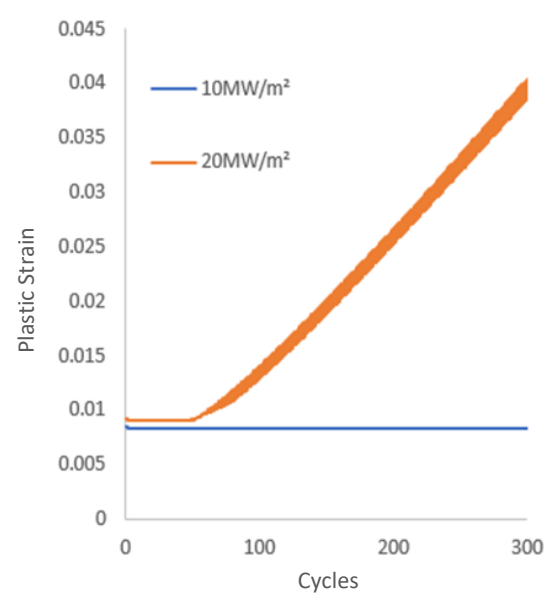

Figure 13 Maximum local strain at $10 \mathrm{MW} / \mathrm{m} 2$ and $20 \mathrm{MW} / \mathrm{m} 2$ over 300 cycles showing local ratcheting in the stress concentration in the gap between adjacent monoblocks

\subsubsection{Global ratcheting}

Figure 14 shows the calculated displacements in the $\mathrm{CuCrZr}$ pipe after 30 cycles of loading from standby to $20 \mathrm{MW} / \mathrm{m}^{2}$ heat load. The history of the maximum displacement is presented in Figure 15 which shows that there is some delay in a "fully" stabilised result (at approximately $0.04 \mathrm{~mm}$ ). It is suggested this delay is possibly caused by elastic follow-up effects, driven mainly by the tungsten and/or shakedown of plastic strains within the $\mathrm{CuCrZr}$ and copper. Note though that any such delay means that identification of a fully stabilised condition retains an element of subjectivity (i.e. is less than ideal) even with the simplest possible material model.

No global ratcheting was observed for the $\mathrm{CuCrZr}$ pipe even when pipe pressures were increased by a factor of 5 . This is because typical through-thickness temperature differentials are insufficient to generate the cyclic plasticity enabling a ratcheting response at low pressures. For materials with less conductivity, global ratcheting is more likely to be a concern. To illustrate the point, Figure 16 \& Figure 17 show a study of ratcheting for the case of a monoblock with heatsink pipe made from stainless steel (i.e. with conductivity approximately $1 / 20^{\text {th }}$ of copper alloys). Figure 16 shows the maximum displacements resulting from cyclic heating at various constant internal pressures. All pressures studied, except the $8.6 \mathrm{MPa}$ case, results in an unstable cyclic response. An estimate of the maximum allowable internal pressure avoiding ratcheting for this case can be determined by interpolating the pressure vs displacement-increment data as shown in Figure 17 (here indicating an allowable pressure of circa $14 \mathrm{MPa}$ )

Conclusion: Assessement is passed (usage not determined)

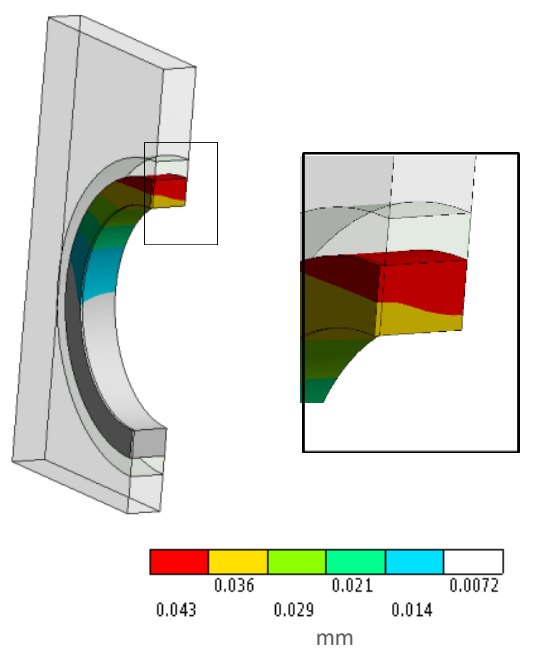

Figure 14 Total displacement $(\mathrm{mm})$ in CuCrZr pipe after 30 cycles from standby to $20 \mathrm{MW} / \mathrm{m}^{2}$ heat load)

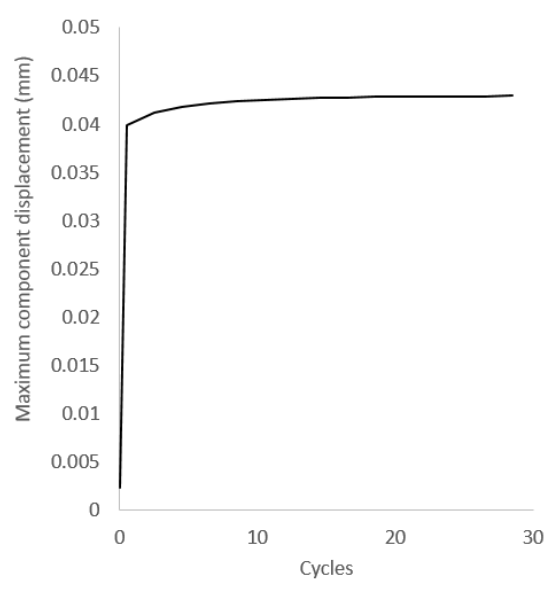

Figure 15 History of maximum displacement $(\mathrm{mm})$ in CuCrZr pipe over 30 cycles from standby to $20 \mathrm{MW} / \mathrm{m} 2$ heat load showing that stabilised conditions are achieved but only after 25 to 30 cycles. 


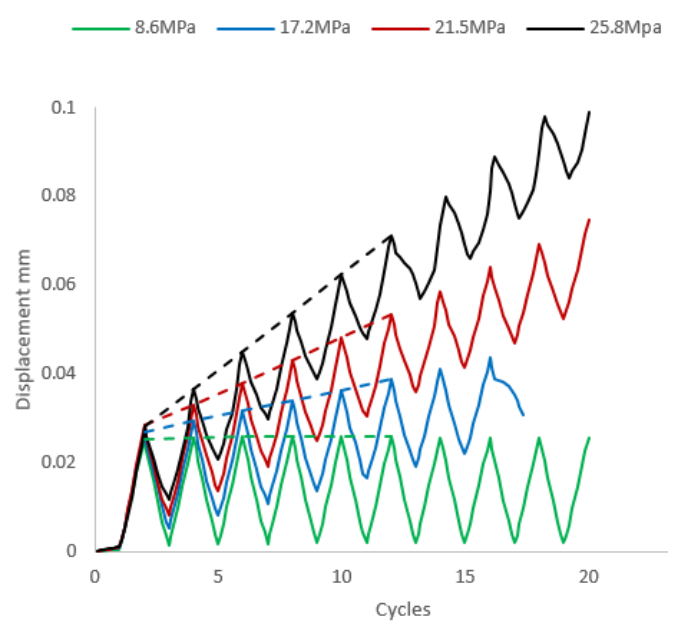

Figure 16 Example cycle by cycle max. displacement ratcheting at various internal pressures in a monoblock with $316 \mathrm{LN}$ pipe of $0.5 \mathrm{~mm}$ wall thickness

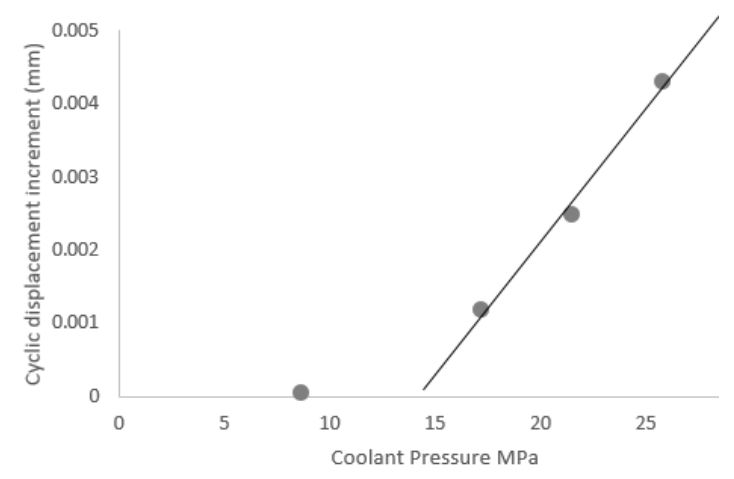

Figure 17 Cyclic displacement increment at various coolant pressures for 316LN pipe (from Figure 13) indicating a pressure limit of approximately $15 \mathrm{MPa}$

\subsubsection{Fatigue}

Figure 18 and Figure 19 shows the total equivalent strain range distribution in the $\mathrm{CuCrZr}$ pipe for the cyclic load step from standby to $10 \mathrm{MW} / \mathrm{m}^{2}$ and standby to $20 \mathrm{MW} / \mathrm{m}^{2}$ respectively. The resulting (design) fatigue life is determined using the data listed in the appendix (Table 8). A summary of the calculated fatigue usage fractions from these and all other cyclic load cases is shown in Table 1 . This indicates that, even under normal standby-to- $10 \mathrm{MW} / \mathrm{m}^{2}$ loads alone, the fatigue criterion is failed $(\mathrm{V}=1.44)$.
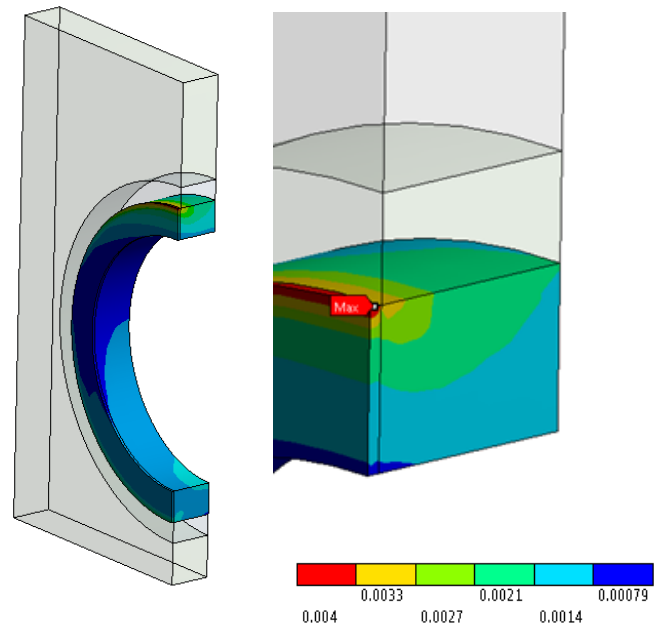

$\Delta \varepsilon$ intensity

Figure 18 calculated intensity of strain range occurring during the step from standby $\left(150^{\circ} \mathrm{C}\right)$ to $10 \mathrm{MW} / \mathrm{m} 2$ heat load, showing a maximum strain range of $0.4 \%$
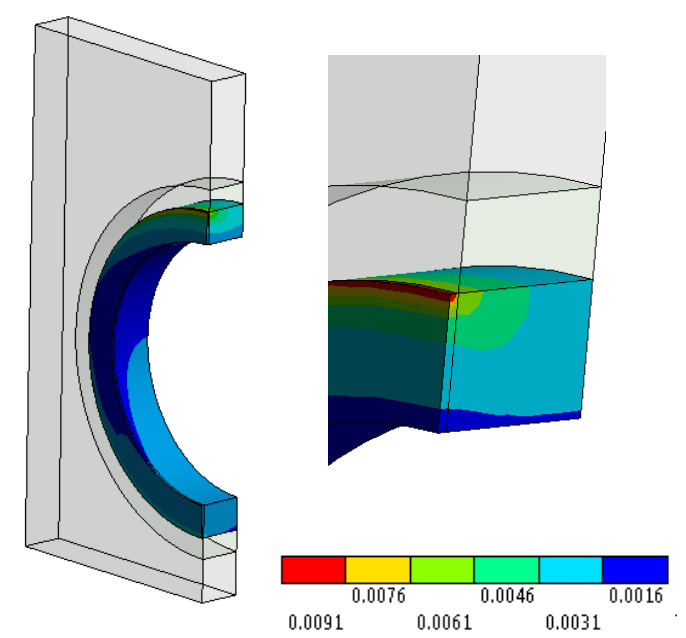

$\Delta \varepsilon$ intensity

Figure 19 calculated intensity of strain range occurring during the step from standby $\left(150^{\circ} \mathrm{C}\right)$ to $20 \mathrm{MW} / \mathrm{m}^{2}$ heat load, showing a maximum strain range of $0.9 \%$ resp.

Table 1 Fatigue usage fraction for all normal operations unirradiated conditions, showing that even under normal $10 \mathrm{MW} / \mathrm{m} 2$ loading, the maximum usage (unit value) is exceeded. (1.44)

\begin{tabular}{cccccc} 
case & $\mathrm{A}$ & $\mathrm{B}$ & $\mathrm{C}$ & $\mathrm{D}$ & $\mathrm{E}$ \\
\hline From & $150^{\circ} \mathrm{C}$ & $20^{\circ} \mathrm{C}$ & $20^{\circ} \mathrm{C}$ & $150^{\circ} \mathrm{C}$ & $20^{\circ} \mathrm{C}$ \\
$\mathrm{To}$ & $10 \mathrm{MW} / \mathrm{m}^{2}$ & 150 & $10 \mathrm{MW} / \mathrm{m} 2$ & $20 \mathrm{MW} / \mathrm{m} 2$ & $20 \mathrm{MW} / \mathrm{m} 2$ \\
\hline$\Delta \varepsilon \%$ & 0.395 & 0.198 & 0.4 & 0.9 & 0.94 \\
$\mathrm{~N}$ & 3465 & 79843 & 3324 & 162 & 143 \\
$\mathrm{Nspec}$ & 5000 & 300 & 300 & 300 & 300 \\
$\mathrm{Vi}$ & 1.44 & 0 & 0.09 & 1.85 & 2.1 \\
$\Sigma \mathrm{Vi}$ & 3.63 & & & &
\end{tabular}

Conclusion: Assessement is failed (usage 363\%) 


\subsection{Assessment of Copper}

The structural integrity assessment of the copper interlayer in the ITER-like design is hampered by an apparent stress/strain discontinuity at the free surface ends of the copper to tungsten joint (Figure 20) indicated by ever-increasing peak strain with increasing mesh density (as shown in Figure 21). Under these circumstances the IAP recommends the hot spot method, but as stated, only if benchmark data were available.

Alternatively, and to enable demonstration of the standard IAP rules for the interlayer, a modified joint design has been created to avoid this singularity (according to the methods outlined by Kelly [8]). This is achieved by creating a scalloped end face to the interlayer as shown in

Figure 22. The strains in the modified design are finite and, as such, can be assessed against the same IAP rules used for assessing the $\mathrm{CuCrZr}$.

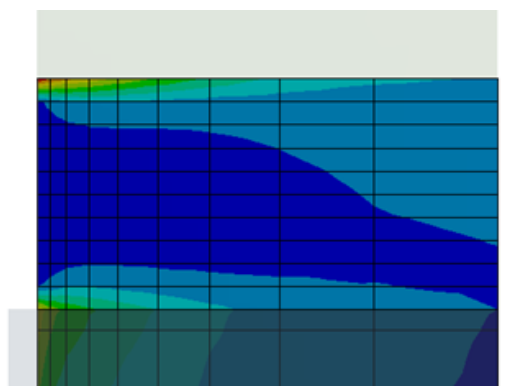

Figure 20 Strain in the copper interlayer at $20 \mathrm{MW} / \mathrm{m} 2$ show strain concentration at surface of dissimilar material joint interfaces (top left)

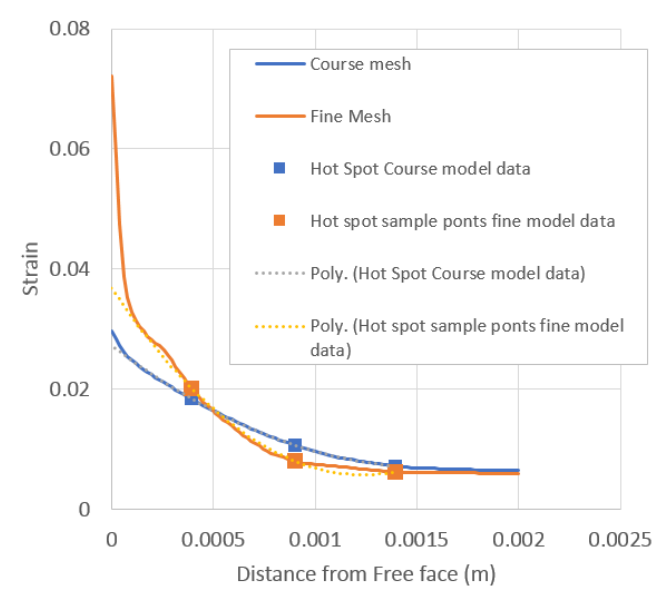

Figure 21 Strain in the copper interlayer at $20 \mathrm{MW} / \mathrm{m} 2$ at different mesh density showing the presence of a strain singularity and hot spot extrapolation of peak stress at copper to tungsten joint free surface

\subsubsection{Exhaustion of ductility}

Figure 23 shows the calculated ductility usage for the modified interlayer design at $20 \mathrm{MW} / \mathrm{m}^{2}$, with maximum value of $29 \%$. This is considerably more than the $\mathrm{CuCrZr}$ max usage but well within requirements.

Conclusion: Assessement is passed (usage 29\%)
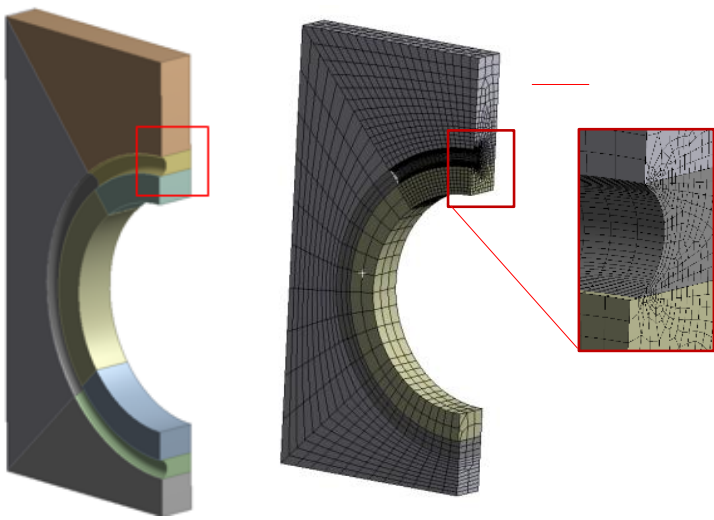

Figure 22 Modified interlayer design with scalloped copper surface to remove dissimilar material joint strain discontinuity (and model implementation used to achieve viable mesh and run times)

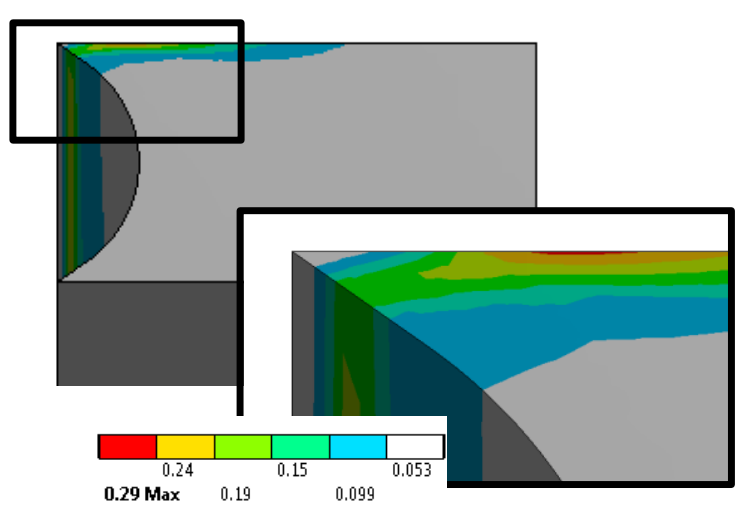

Figure 23 Ductility usage for Copper at 20MW/m²

\subsubsection{Fast fracture}

No assessment of fast fracture was deemed necessary for copper in its soft unirradiated state.

\subsubsection{Ratcheting}

\subsubsection{Local ratcheting}

The copper shows a similar local strain ratcheting response as that shown by the CuCrZr in Figure 13. In this case however the strain levels are far more significant rising from an initial value of $19 \%$ to over $100 \%$ after 300 cycles. Furthermore, the maximum available strain (nominally $139 \%$ in the uniaxial case) is reduced by significant triaxial stress factor of $0.19(\mathrm{Ktf}=0.19)$, and as a result total strain usage is determined to be 3.5. This suggest voids or cracks might be created even in this the unirradiated case. As for the $\mathrm{CuCrZr}$, the result must be viewed with caution pending further validation of the material model.

Conclusion: Assessement is failed (usage $=3.5$ )

\subsubsection{Global ratcheting}

Under normal operating conditions, ratcheting in the interlayer is not expected if the pipe does not ratchet (since both experience the same driving force of pipe pressure), and Figure 
24 shows that the calculated maximum displacement achieves a near stabilised value in the first step $(0.045 \mathrm{~mm})$. Nonetheless the results still show some small fluctuation in subsequent cycles as seen in the $\mathrm{CuCrZr}$ implying some "shakedown" effects within the model (as discussed above).

Conclusion: Assessement is passed (usage not determined)

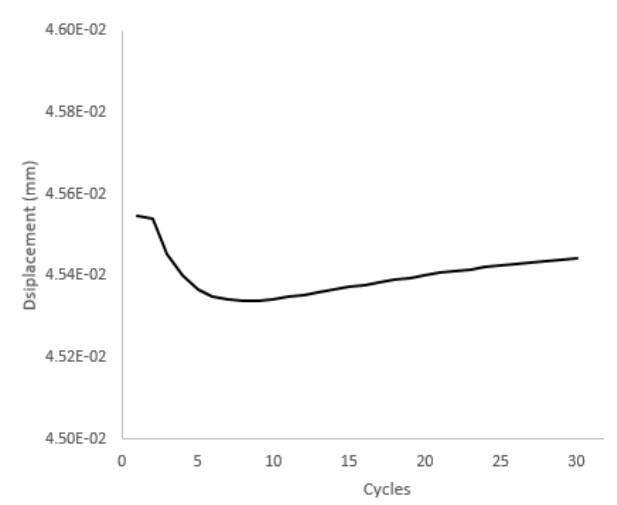

Figure 24 study of max displacement history in the scalloped interlayer at $20 \mathrm{MW} / \mathrm{m}^{2}$

\subsubsection{Fatigue}

The calculated cyclic strain range in cycles from standby to $20 \mathrm{MW} / \mathrm{m}^{2}$ in the scalloped interlayer is $2.1 \%$ ( Figure 25). This indicates that this load condition alone is sufficient to cause failure according to the recommended design curve (SDC-IC) (with a design life of just 25 cycles and fatigue usage of 12). Moreover, even using the average test life data of Liu [20], failure is expected after just 250 cycles. Similar fatigue usage is found for the normal operating $10 \mathrm{MW} / \mathrm{m}^{2}$ case. The assessment indicates that improvement is required.

Conclusion: Assessement is failed.

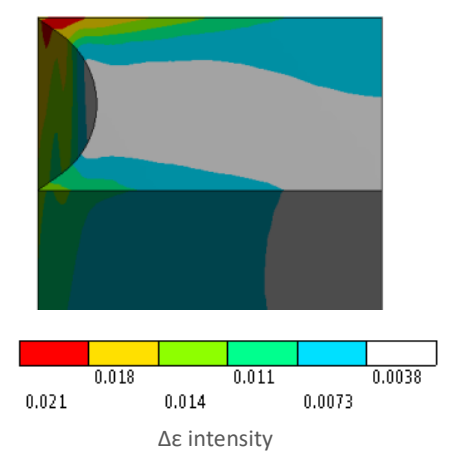

Figure 25 total strain increment in the scalloped interlayer cyclic loading from standby to $20 \mathrm{MW} / \mathrm{m}^{2}$

\subsection{Assessment of Tungsten}

\subsubsection{Recrystalised layer}

Figure 26 shows the result of the thermal model of a $20 \mathrm{MW} / \mathrm{m}^{2}$ heat load case used to identify the recrystalised tungsten material. It also shows the partition of the FE model created to allow allocation of elastoplastic material properties to the recrystalised zone.

To identify the plastic strain above and below the DBTT, a transient thermal analysis of the load case was carried out to determine the thermal field when the temperature at the strain concentration crosses the DBTT. This thermal field was then used to determine the associated "reference" strain distribution at the DBTT point, from which differential strains relative to the standby and max heat load condition were determined.

Figure 27 shows the differential strains calculated for the example ITER-like design above and below the DBTT with maximum values of $0.14 \%$ and $0.07 \%$ respectively. The fatigue lives of each case are determined from the Manson Coffin data shown in appendix $\mathrm{A}$ of stress relieved tungsten at $815^{\circ} \mathrm{C}$ and $20^{\circ} \mathrm{C}$ respectively (following the method of $\mathrm{Li}[15]$ ). Under these conditions the fatigue life of tungsten for periods below the DBTT is calculated to be just 88 cycles (for this $20 \mathrm{MW} / \mathrm{m} 2$ condition) leading to a fatigue usage fraction of 3.4 (for the assumed 300 cycle requirement).

Conclusion: Assessement is failed (usage 340\%)
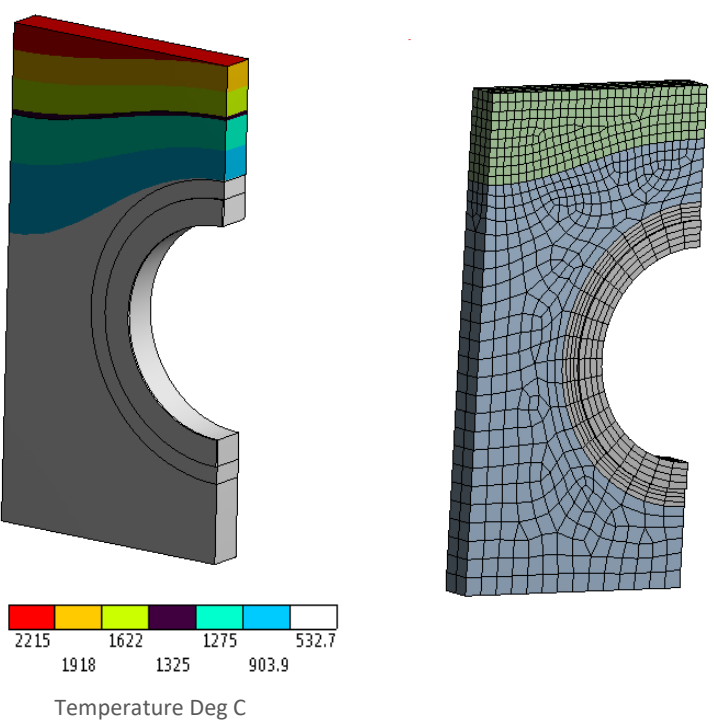

Figure 26 Location of line demarking $1300 \mathrm{C}$ used to define the recrystallised tungsten boundary, and the remodelling of the recrystallized zone (green) with elastic perfectly-plastic material properties
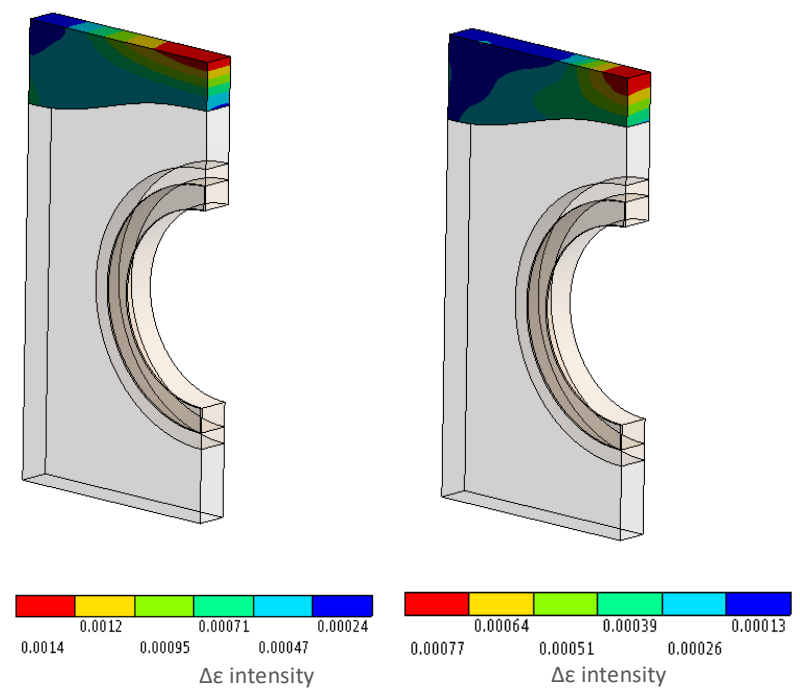

Figure 27 delta total strain in cooling phase above $800 \mathrm{C}(\Delta \varepsilon$ $=.14 \%)$ and in cooling phase from $800 \mathrm{C}$ to standby $(\Delta \varepsilon=.07 \%)-$ fatigue strain above and below DBTT 


\subsubsection{Ultimate strength}

Figure 28 shows that at $20 \mathrm{MW} / \mathrm{m}^{2}$ in the unirradiated condition the maximum value of maximum principal stress (732MPa) exceeds the allowable stress of 489Mpa (An effective usage of 1.49). There is thus a danger of brittle fracture.

Conclusion: Assessement is failed (usage 149\%)
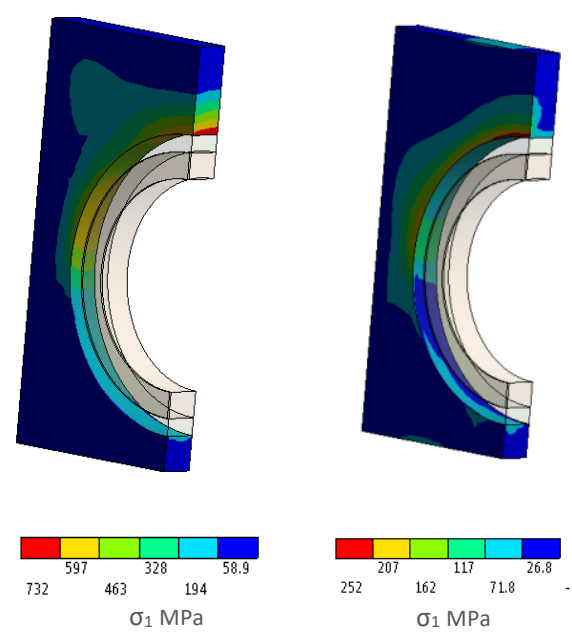

Figure 28 Maximum principal stress in the tungsten at 20MW/m2 and standby

\subsection{Summary of assessment results}

Table 2 summarises all the above elastoplastic assessment results for the example ITER-like PFC design. Most of the rules are passed except fatigue and tungsten brittle fracture. Fatigue is failed by a not-insignificant margin, especially for the copper. Note however this assessment of the copper was only possible after modification of the tungsten copper interface geometry.

It is also suggested that the perfectly constrained single monoblock model may exaggerate the monoblock gap stress concentration effects. A more precise representation of the support geometry may lead to an improved fatigue life estimation.

Table 2 summary of elastoplastic assessment of the ITER like monoblock in its unirradiated state in terms of usage fractions (rule is failed if $>1$ )

\begin{tabular}{|c|c|c|c|c|}
\hline & \multicolumn{2}{|c|}{$\mathrm{CuCrZr}$} & \multirow{2}{*}{$\begin{array}{l}\mathrm{Cu} \\
\text { (scallop) } \\
20 \mathrm{MW} / \mathrm{m}^{2}\end{array}$} & \multirow[t]{2}{*}{ Tungsten } \\
\hline & Standby & $20 \mathrm{MW} / \mathrm{m}^{2}$ & & \\
\hline ductility & 0.038 & 0.048 & 0.29 & \\
\hline fracture/UTS & 0.65 & 0.63 & - & 1.49 \\
\hline local ratchet & \multicolumn{2}{|c|}{0.095} & 3.4 & \\
\hline global ratchet & \multicolumn{2}{|c|}{ pass } & pass & \\
\hline fatigue & \multicolumn{2}{|c|}{3.63} & $>12 / 1.2^{(1)}$ & 3.4 \\
\hline
\end{tabular}

\section{Summary}

\subsection{Overview}

This paper presents guidelines (known as the Inelastic Analysis Procedure-IAP) for the recommended method of assessing by analysis the structural integrity of PFCs under high heat flux loads. The objective is to be able to justify the merits a proposed DEMO concept design without complete reliance on testing.

The use of analysis to provide such a justification is particularly important when considering the irradiated case. In DEMO, the effects of irradiation are potentially very significant and perhaps lead to the worst-case condition. Since it is impractical to physically test irradiated components at the concept phase of development, it appears only analysis is capable of providing (or estimating) the required data for judging a design concept's irradiated performance.

The IAP aims to overcome two main shortfalls in existing methods of analysis-based PFC design-assessment. These shortfalls are that there are no rules to assess armour or interlayer failure and that the existing elastic method for assessing the structural (pipe) component gives incorrect stress values.

\subsubsection{Rules}

To allow prediction of the armour failure, specific assessment rules have been devised, (since there are no formal code rules for the structural integrity assessment of brittle materials). So far two rules have been created: One based on the work of $\mathrm{Li}$ [15] for the prediction of deep cracking and the second based on the textbook Rankine criterion using UTS. The deep cracking rule assesses plastic strain fatigue in recrystallised tungsten when above the DBTT. These rules should be viewed as provisional pending further work.

To overcome the specific issues in the analysis of the pipe (and to allow analysis of the interlayer) elastoplastic methods are presented. These methods overcome the problems caused by the multi-material nature of PFCs (with the associated mix of dissimilar CTEs and yield strengths). They also allow the explicit simulation of the changes in material properties due to irradiation so that accumulated strain effects before and after irradiation can be accounted for.

In this paper the recommended low temperature (elastoplastic) code rules have been detailed. They comprise two rules for armour (as above) and four rules for the ductile materials (categorized as SDC-IC). These are as follows:

1. An exhaustion-of-ductility rule based on ASME with an adaptation from SDC-IC, (this rule is particularly important for assessing loss of integrity due to the severely limited ductility associated with irradiated materials);

2. A fast fracture rule based on SDC-IC (necessary to expose failure of "embrittled" irradiated materials containing minor defects);

3. A conventional fatigue rule (primarily exercised by stress concentrations in gaps between monoblocks) and

4. A ratcheting rule designed to capture two failure modes. Firstly by "local ratcheting" where strains locally grow progressively to exceed material limits (and potential crack initiation) and the second by "global ratcheting" 
where, for example, pipe wall thinning develops leading to plastic collapse (this is particularly important if low conductivity materials such as stainless steel or Eurofer are used).

The paper has also presented specific analysis methodologies to cover such things as simulation of manufacture (to account for and include effects of residual stress and manufacturing strains) and the use of usage-fractions to account for variability of ductility limits before and after irradiation (where accumulated strain is important).

\subsubsection{Example application and results}

The rules have been demonstrated by an example structural integrity assessment of a monoblock pipe, interlayer and armour. In this paper only the unirradiated case is studied where fatigue is exposed as a potential failure mechanism for all components (fatigue crack initiation in the armour would consequently cause deep cracking fast fracture). In a follow-up paper the rules are used to estimate component performance in the irradiated embrittled case where exhaustion of ductility and fast fracture are more significant.

The example analyses also expose other notable aspects of monoblock assessment. Firstly, that multiaxial stress effects in ductility usage are significant in further reducing potentially already limited ductility. This suggest that multiaxial effects need to be considered in the assessment of other failure mechanisms. Secondly the examples confirm that strain singularities complicate the assessment of current monoblock designs, however since these effectively indicate an extreme stress concentration, it is suggested that these should be removed by a design change rather than attempt a bespoke failure assessment 'device' such as the hot spots methods.

The example analyses also show that in some rules there are a number of independent local effects contributing to a local usage-fraction maximum. For example, ductility usage, which is dependent on temperature dependent strain limits, locally variable triaxiality and locally variable stress. In these circumstances, contour plots of the computed usage (combining all effects) were created, so that the location of maximum values could be easily identified (and associated maximum value determined).

The results of the local ratchetting assessment should be viewed as indicative only, because of the concerns relating to the ability of material models to predict progressive local strain growth accurately. Further validation tests will be required to demonstrate acceptance. Nonetheless this is an improvement on existing elastic assessment where local ratchetting is not assessed.

\subsubsection{Alternative materials}

The paper has described in detail rules and methodologies that are illustrated by reference to the $\mathrm{CuCrZr} /$ tungsten monoblock PFC. Nonetheless the rules and methodologies are directly applicable other potential PFC (structural) materials such as Eurofer or variants. (Indeed, an example global ratchetting assessment has been shown for a case with steel pipe). Although specific rules \& methods have been devised for the (tungsten) armour, it is the intention that generally the IAP provides guidelines for the assessment of all PFCs, irrespective of the particular design and/or materials used.

\subsubsection{Irradiation and creep assessment}

In part 2 of this paper, an assessment of the ITER-like component in its irradiated state is presented using the above rules. In this case stress strain curves are modified and irradiated allowable applied. Consideration for the accumulation of strain before and after irradiation is given. In part 3 a creep assessment is made using explicit inelastic simulation of creep strain accumulation and assessment of rupture under multiaxial stress conditions.

\subsection{Conclusion}

It is argued that the proposed analysis procedure (with its inelastic techniques and devised armour rules) provides a significant step forward towards a reliable method of justifying by analysis the expected structural performance of DEMO PFC designs. Such analysis methods are deemed essential for DEMO concept development in order to estimate irradiated performance in the absence of test data.

These methods will be further validated and developed using the observations from ongoing PFC testing within EUROfusion's divertor PFC concept development program.

\subsection{Further work}

The ongoing development of the IAP will focus on the following areas:

1. Armour assessment: Increasing the range of armour failure rules, through further observations of existing armour failures or specific failure testing.

2. Ratcheting: many aspects of local ratcheting assessment need improvement. This includes further validation of material models and validation of the local material failure mechanism (in a manner that can be distinguished from fatigue failure).

3. New materials: methods need to be devised illustrating how the structural integrity of new materials such as tungsten fibre reinforced copper can be assessed.

4. Joint strength: The current procedure assumes joint strength exceeds that of the parent material (in all damage mechanism). It is suggested that joint strength rules could be created by a detailed study of the susceptibility of each joint type (joined material and joining method combination) to fatigue, ductility usage, fast fracture.

5. Multiaxial effects: Investigate if the significance of multiaxial effects shown in ductility usage also extends to other rules, for example fatigue.

6. Plastic collapse: Include example assessments of plasma disruption EM load cases.

7. Alternative materials: use the IAP to demonstrate the performance of monoblocks constructed with Eurofer pipe relative to that achieved with $\mathrm{CuCrZr}$. 


\section{Acknowledgements}

This work has been carried out within the framework of the EUROfusion Consortium and has received funding from the Euratom research and training programme 2014-2018 and 20192020 under grant agreement No 633053, and from the RCUK Energy Programme [grant number EP/I501045]. To obtain further information on the data and models underlying this paper please contact PublicationsManager@ccfe.ac.uk. The views and opinions expressed herein do not necessarily reflect those of the European Commission.

The author would like to acknowledge the assistance given by Alberto Tallarigo and Vaughan Thompson at CCFE for their advice on rule development.

\section{References}

[1] J.-H. You et al., European divertor target concepts for DEMO: Design rationales and high heat flux performance, Nuclear Materials and Energy 16 (2018) 1-11.

[2] M. Fursdon, J.-H. You, T. Barrett, M. Li, A hybrid analysis procedure enabling elastic design rule assessment of monoblock-type divertor components, Fus. Eng. Des. 135 (2018) 154-164.

[3] ITER SDC-IC_222RHC_v3_0, G 74 MA 8 01-05-28 W 0.2, 2012.

[4] M. Gorley, M. Fursdon, and M. Kalsey, Integrating Materials Engineering and Design for Fusion, IEEE Transactions On Plasma Science, Vol. 46, No. 5, May 2018.

[5] M. Fursdon, M. Li, J-H You, Enhancements in the structural integrity assessment of plasma facing components. In publication Fus. Eng. Des. (2019).

[6] A. Li-Puma, Potential and limits of water cooled divertor concepts based on monoblock design as possible candidates for a DEMO reactor, Fus Eng. Des. 88 (2013) 1836- 1843.

[7] EN13445-3-2:2002 (E) Issue 13 (2005-03) sect 18.6.1.

[8] P. A. Kelly et al. The design of joints between elastically dissimilar components. Journal of strain analysis Vol 27 1992 IMechE 1992.

[9] M. Li, J-H You, Structural impact of creep in tungsten monoblock divertor target at $20 \mathrm{MW} / \mathrm{m}^{2}$, Nuclear Materials and Energy 14 (2018) 1-7.

[10] ASME Section VIII div 2.

[11] V. Thompson, Z. Vizvary, The "ductility exhaustion" method for static strength assessment of fusion structures. Fusion Engineering and Design 98-99 (2015) 1638-1642.

[12] J. Rudolph et al., Local ratcheting by elastic-plastic FEA criteria and code-based approaches, Proceedings of the ASME 2001 pressure Vessels \& Piping Division Conference July 2011.

[13] R. Halim, J Sedlak, M Sofer, Phenomenological Modelling of Cyclic Plasticity. www.intechopen.com

[14] V.V Silberschmidt et al., On material immanent ratcheting of two-phase materials under cyclic purely thermal loading, Archive of Applied Mechanics (1999) 727-757 Springer Verlag (1999)
[15] M. Li, J.-H You, Interpretation of the deep cracking phenomenon of tungsten monoblock targets observed in high-heat-flux fatigue tests at $20 \mathrm{MW} / \mathrm{m}^{2}$, Fus. Eng. Des. 101 (2015) 1-8.

[16] E.N. Sieder, G.E. Tate, Heat transfer and pressure drop of liquids in tubes, Ind. Eng. Chem. 28 (12) (1936) 1429-1435.

[17] T.D. Marshall, et al., Modelling the Nukiyama curve for water-cooled fusion divertor channels Fusion Technology, Fusion Technol. 39 (2001).

[18] U.W. Mszanowski Thermprop 5.2 A thermohydraulic properties program for heat transfer design evaluations based on the eupiter code version 4.2 EFDA June 2006.

[19] M. Miskiewicz, J.-H. You, Impact of plastic softening of over-aged $\mathrm{CuCrZr}$ alloy heat sink tube on the structural reliability of a plasma-facing component, Fus. Eng.Des. 83 (2008) 66-71.

[20] K.C. Liu , C.M. Loring, Low-cycle fatigue behaviour of oxygen-free high-conductivity copper at $300^{\circ} \mathrm{C}$ in high vacuum Original Research Article, Journal of Nuclear Materials, Volume 122, Issues 1-3, 2 May 1984, Pages 783788.

[21] R.E. Schmunk and G. E. Korth, "Tensile and Low Cycle Fatigue measurements on Cross-Rolled Tungsten", Journal of Nuclear Materials, 103 \& 104 (1981), pp. 943-948.

[22] ITER SDC-IC Appendix A G 74 MA 8 01-05-28 W 0.22012

[23] J.-H. You, M. Miskiewicz, Material parameters of copper and $\mathrm{CuCrZr}$ alloy or cyclic plasticity at elevated temperatures J. Nucl. Mater. 373 2008) 269-274.

[24] T. Hiraia et al, Test Design optimization of the ITER tungsten divertor vertical targets Fus. Eng. Des. 127 (2018) 66-72.

[25] M. Merola et al, Overview and status of ITER internal components, Fus. Eng. Des. 89 (2014) 890-895.

[26] J.-H. You, et al, Conceptual design studies for the European DEMO divertor: Rationale and first results, Fus. Eng. Des. 109-111 (2016) 1598-1603.

[27] P. Gavilaa, High heat flux testing of EU tungsten monoblock mock-ups for the ITER divertor, Fus. Eng. and Des. 98-99 (2015) 1305-.

[28] F. Crescenzi, et al., FEM and thermal fatigue testing comparison of ITER-like divertor PFUs mock-ups for DEMO, Fus. Eng. Des. 123 (2018) 558-562.

[29] S.A. Fabritsiev et al. Effect of the irradiation-annealingirradiation cycle on the mechanical properties of pure copper and copper alloy, J. Nucl. Mater 324 (2004) 23-32.

[30] J. Rudolph, et al., Local ratchetting by elasto plastic FEA criteria and code-based approaches, Proceedings of the ASME 2011 Pressure Vessel and Piping Division Conference PVP2011-57229 Baltimore.

[31] Z. Sun et al., Post examination of tungsten monoblocks subjected to high heat flux tests of ITER full tungsten divertor qualification program, Fus. Eng. Des. 121 (2017) 60-69.

[32] G. Pintsuk et al., High heat flux testing of first wall mockups with and without neutron irradiation, Nuclear Materials and Energy 9 (2016) 41-45.

[33] RCC-MR. Design and construction rules for power generations stations. Edition (2007). 
[34] Fursdon et al., The development and testing of the thermal break divertor monoblock target design delivering $20 \mathrm{MW}$ m-2 heat load capability, 2017 Phys. Scr. (2017) 014042.

[35] E. Visca et al, Fabrication and acceptance of ITER vertical target divertor full scale plasma facing units fabricated by HRP, Fus. Eng. Des. 124 (2017) 191-195.

[36] H. Greuner et al., progress in high heat flux testing of European DEMO divertor mock-ups, in publication Fus. Eng. Des. 2018.
[37] Peng Liu et al., Study on creep fatigue of heat sink in W/RAFM divertor for CFETR, Fus. Eng. Des. 137 (2018), 390-395

\section{Appendix: Materials properties and limit data}

Table 3 Summary of properties of considered materials at selected temperatures (taken from [22])

\begin{tabular}{cccccc}
\hline \multirow{2}{*}{ Copper } & $\begin{array}{c}\text { Temperature } \\
\left({ }^{\circ} \mathrm{C}\right)\end{array}$ & $\begin{array}{c}\text { Coefficient of } \\
\text { Thermal } \\
\text { Expansion }\left(1 /{ }^{\circ} \mathrm{C}\right)\end{array}$ & $\begin{array}{c}\text { Young's Modulus } \\
(\mathrm{MPa})\end{array}$ & $\begin{array}{c}\text { Thermal } \\
\text { Conductivity } \\
(\mathrm{W} / \mathrm{mmK})\end{array}$ & Poisson's ratio \\
\hline \multirow{2}{*}{$\mathrm{CuCrZr}$} & 20 & $1.68 \mathrm{E}-05$ & 117000 & 0.401 & 0.33 \\
& 400 & $1.82 \mathrm{E}-05$ & 98000 & 0.374 & 0.33 \\
\hline \multirow{2}{*}{ Tungsten } & 20 & $1.67 \mathrm{E}-05$ & 127500 & 0.318 & 0.33 \\
& 450 & $1.82 \mathrm{E}-05$ & 110000 & 0.347 & 0.33 \\
\hline
\end{tabular}

Elastoplastic data for global ratcheting Copper yield stress $=30 \mathrm{MPa} . \mathrm{CuCrZr}=220 \mathrm{MPa}$ (average of data from [22])

Table 4 Monotonic rule assessment Chaboche model parameter values for Copper and CuCrZr elasto-plastic kinematic hardening model. (manual parameter fit to tests data from [22])

\begin{tabular}{ccccccccc}
\hline & $\begin{array}{c}\text { Temperature } \\
\text { (C) }\end{array}$ & $\begin{array}{c}\text { Yield } \\
\text { Stress } \\
\text { (MPa) }\end{array}$ & $\begin{array}{c}\text { Material } \\
\text { Constant } \\
\text { C1 (MPa) }\end{array}$ & $\begin{array}{c}\text { Material } \\
\text { Constant } \gamma 1\end{array}$ & $\begin{array}{c}\text { Material } \\
\text { Constant } \\
\text { C2 (MPa) }\end{array}$ & $\begin{array}{c}\text { Material } \\
\text { Constant } \gamma 2\end{array}$ & $\begin{array}{c}\text { Material } \\
\text { Constant } \\
\text { C3 (MPa) }\end{array}$ & $\begin{array}{c}\text { Material } \\
\text { Constant } \gamma 3\end{array}$ \\
\hline \multirow{2}{*}{ Copper } & 20 & 45 & 40000 & 7500 & 11000 & 846 & 1000 & 55 \\
& 400 & 18 & 10000 & 4000 & 2500 & 450 & 250 & 55 \\
\hline \multirow{2}{*}{$\mathrm{CuCrZr}$} & 20 & 220 & 22000 & 1000 & 2000 & 40 & & \\
& 300 & 160 & 33000 & 1500 & 1600 & 40 & & \\
\end{tabular}

Table 5 Cyclic rule assessment Chaboche model parameter values for Copper and CuCrZr elasto-plastic kinematic hardening model. (manual parameter fit to tests data [23] $(\mathrm{Cu})$ and [22] $(\mathrm{CuCrZr})$

\begin{tabular}{cccccccccc}
\hline & Temperature & Yield & Material & Material & Material & Material & Material & Material \\
Ctress & Constant C1 & Constant & Constant & Constant & Constant & Constant \\
& $(\mathrm{C})$ & $(\mathrm{MPa})$ & $(\mathrm{MPa})$ & $\gamma 1$ & $\mathrm{C} 2(\mathrm{MPa})$ & $\gamma 2$ & $\mathrm{C} 3(\mathrm{MPa})$ & $\gamma 3$ \\
\hline \multirow{2}{*}{ Copper } & 20 & 90 & 80000 & 7500 & 22000 & 846 & 2000 & 55 \\
& 400 & 55 & 20000 & 4000 & 5000 & 500 & 500 & 55 \\
\hline \multirow{2}{*}{$\mathrm{CuCrZr}$} & 20 & 180 & 300000 & 4000 & 30000 & 825 & 6000 & 45 \\
& 350 & 152 & 200000 & 5000 & 30000 & 1000 & 6000 \\
\hline
\end{tabular}

Table 6 Yield data for recrystalised Tungsten elastic perfectly-plastic material model [15]

\begin{tabular}{cc}
\hline Temperature $(\mathrm{C})$ & Yield Stress $(\mathrm{MPa})$ \\
\hline 20 & 377 \\
400 & 362 \\
1200 & 223 \\
2000 & 57 \\
2500 & 57 \\
\hline
\end{tabular}


Table 7 Limit data for Copper CuCrZr (from [22])

\begin{tabular}{|c|c|c|c|c|}
\hline & $\begin{array}{l}\text { Temperature } \\
\text { (C) }\end{array}$ & $\begin{array}{c}\text { True strain } \\
\text { at rupture } \\
(\%)\end{array}$ & $\begin{array}{l}\mathrm{JQmin} \\
\mathrm{KJ} / \mathrm{m}^{2}\end{array}$ & 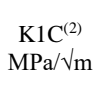 \\
\hline \multirow{5}{*}{$\mathrm{CuCrZr}$} & 20 & 124 & 206 & 157 \\
\hline & 100 & 112 & 154 & 136 \\
\hline & 200 & 99 & 114 & 117 \\
\hline & 300 & 87 & 99 & 109 \\
\hline & 400 & 76 & No data & No data \\
\hline \multirow{5}{*}{ Copper } & 20 & 120 & No data & \\
\hline & 100 & 120 & No data & \\
\hline & 250 & 139 & No data & \\
\hline & 300 & No data ${ }^{1}$ & No data & \\
\hline & 400 & No data ${ }^{1}$ & No data & \\
\hline
\end{tabular}

Table 8 Fatigue data for $\mathrm{CuCrZr}$, Copper and stress relieved tungsten (recommended "design" data or average test "life" data).

\begin{tabular}{cccccc} 
& $\begin{array}{c}\text { Copper } \\
\text { design [22] }\end{array}$ & $\begin{array}{c}\text { Copper life } \\
{[20]}\end{array}$ & $\begin{array}{c}\mathrm{CuCrZr} \\
\text { design }[22]\end{array}$ & $\begin{array}{c}\text { W life at } \\
20^{\circ} \mathrm{C}[21]\end{array}$ & $\begin{array}{c}\text { W life at } \\
815^{\circ} \mathrm{C}[21]\end{array}$ \\
\hline Cycles & $\begin{array}{c}\text { total strain } \\
\text { range \% }\end{array}$ & $\begin{array}{c}\text { Total } \\
\text { strain } \%\end{array}$ & $\begin{array}{c}\text { total strain } \\
\text { range } \%\end{array}$ & $\begin{array}{c}\text { plastic strain } \\
\text { range \% }\end{array}$ & $\begin{array}{c}\text { plastic strain } \\
\text { range \% }\end{array}$ \\
\hline 10 & 2.7 & & 2.29 & 0.125297 & 11.78905 \\
40 & 1.35 & & 1.395 & 0.082665 & 6.230621 \\
100 & 0.88 & 3.0 & 1.026 & 0.062797 & 4.087699 \\
400 & 0.5 & 1.6 & 0.672 & 0.041431 & 2.160386 \\
1000 & 0.37 & 1.3 & 0.526 & 0.031473 & 1.417356 \\
$4.00 \mathrm{E}+03$ & 0.25 & 0.8 & 0.376 & 0.020765 & 0.749085 \\
$1.00 \mathrm{E}+04$ & 0.21 & 0.6 & 0.308 & 0.015774 & 0.49145 \\
$4.00 \mathrm{E}+04$ & 0.15 & 0.4 & 0.2233 & 0.010407 & 0.259736 \\
$1.00 \mathrm{E}+05$ & 0.12 & 0.33 & 0.1852 & 0.007906 & 0.170404 \\
\hline
\end{tabular}

